\title{
Experimental determination of the micro-scale strength and stress-strain relation of an epoxy resin
}

Zike, Sanita; Sørensen, Bent F.; Mikkelsen, Lars Pilgaard

Published in:

Materials \& Design

Link to article, DOI:

10.1016/j.matdes.2016.02.102

Publication date:

2016

Document Version

Peer reviewed version

Link back to DTU Orbit

Citation (APA):

Zike, S., Sørensen, B. F., \& Mikkelsen, L. P. (2016). Experimental determination of the micro-scale strength and stress-strain relation of an epoxy resin. Materials \& Design, 98, 47-60.

https://doi.org/10.1016/j.matdes.2016.02.102

\section{General rights}

Copyright and moral rights for the publications made accessible in the public portal are retained by the authors and/or other copyright owners and it is a condition of accessing publications that users recognise and abide by the legal requirements associated with these rights.

- Users may download and print one copy of any publication from the public portal for the purpose of private study or research.

- You may not further distribute the material or use it for any profit-making activity or commercial gain

- You may freely distribute the URL identifying the publication in the public portal

If you believe that this document breaches copyright please contact us providing details, and we will remove access to the work immediately and investigate your claim. 


\section{Accepted Manuscript}

Experimental determination of the micro-scale strength and stress-strain relation of an epoxy resin

Sanita Zike, Bent F. Sørensen, Lars P. Mikkelsen

PII:

S0264-1275(16)30246-5

DOI:

doi: 10.1016/j.matdes.2016.02.102

Reference:

JMADE 1452

To appear in:

Received date: 17 October 2015

Revised date: $\quad 22$ February 2016

Accepted date: $\quad 23$ February 2016

Please cite this article as: Sanita Zike, Bent F. Sørensen, Lars P. Mikkelsen, Experimental determination of the micro-scale strength and stress-strain relation of an epoxy resin, (2016), doi: 10.1016/j.matdes.2016.02.102

This is a PDF file of an unedited manuscript that has been accepted for publication. As a service to our customers we are providing this early version of the manuscript. The manuscript will undergo copyediting, typesetting, and review of the resulting proof before it is published in its final form. Please note that during the production process errors may be discovered which could affect the content, and all legal disclaimers that apply to the journal pertain. 


\title{
Experimental determination of the micro-scale strength and stress-strain relation of an epoxy resin
}

\author{
Sanita Zike, Bent F. Sørensen, Lars P. Mikkelsen \\ Composites and Materials Mechanics Section, Department of Wind Energy, Technical University of Denmark, \\ Risф Campus, 4000 Roskilde, Denmark
}

\begin{abstract}
An approach is developed for determining the stress-strain law and a failure stress appropriate for micromechanical models of polymer materials. Double cantilever beam test specimens, made of an epoxy polymer with notches having finite root radius, were subjected to pure bending moments in an environmental scanning electron microscope. The recorded images were used to measure strains around the notch with a 2D digital image correlation method. The strain in front of the notch was found to reach $20 \%$ before the failure initiation, which significantly exceeds the failure strain measured at the macro-scale (5-6\%). The hardening exponent of a power law hardening material was obtained by the use of the J-integral, estimating the strain energy density around the notch. The hardening exponent was found to be within the range of 5 to 6 and the corresponding micro-scale failure stress was in the range of 220-300 MPa. Furthermore, the experimentally measured strains around the notch edge were compared with the strain field of the HRR-field. In addition, our experimental study shows that the strain fields between the notches with different notch root radii are comparable, if all length parameters are normalized with the width of deformed notch.
\end{abstract}

Keywords: micro-scale test, micro-mechanical models, in-situ testing, polymer/fibre composites, epoxy matrix

\section{Introduction}

Polymer/fibre composite materials are often used in structural load carrying components. For instance, in the wind energy industry, polymer/fibre composites are used in rotor blades, due to their high stiffness, low density, and good fatigue performance [1,2]. The fibres are usually designed to carry the main load of the composite structure. Some of the microscopic processes, however, are greatly dependent on the matrix behaviour, e.g. loading transverse to the fibres. At the micro-scale, the failure of the matrix initiates from a flaw in the matrix or at a fibre/matrix interface leading to the fibre-matrix debonding and fibre cracking. These micro-scale events result in a macro-scale failure, e.g. delamination between plies, reducing performance of the composite structure [3]. For this reason, micro-mechanical models are often used to study the effect of micro-scale material properties and microscopic defects on the microscopic damage evolution.

In this paper, we aim to determine the matrix material properties (the stress-strain law and the failure stress) to be used in micro-mechanical models for the simulation of progressive damage evolution in composite materials. First, in order to characterize micro-mechanical behaviour of matrix, its properties have to be 
determined at the relevant length scale. The macroscopic stress-strain law and tensile strength of a material is not sufficient for use in micro-mechanical modelling. Consider a simple uniaxial tensile testing of a material, shown in Fig. 1a, that fails by brittle fracture, i.e. from pre-existing flaws. At the macro-scale, we consider the material as well as stress and strain fields to be uniform, i.e. the same at any point within the gauge section. Model wise, the macroscopic failure stress would be determined simply as the force at failure, $F_{u}$, divided by the cross-section area, $A$, i.e. the average failure stress $\tilde{\sigma}_{u}=F_{u} / A$. Likewise, the macroscopic failure strain $\tilde{\varepsilon}_{u}$ will be determined from the macroscopic deformation, e.g. the elongation $\Delta L$ measured by an extensometer with a certain initial gauge length, $L_{o}, \tilde{\varepsilon}_{u}=\Delta L / L_{o}$. A strain gauge will also give the strain averaged over its gauge length. These strength values are appropriate for modelling structures at the macro-scale.

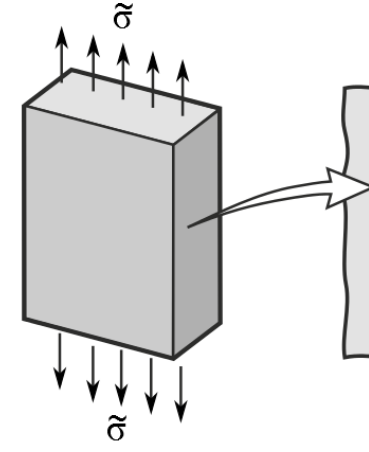

(a)

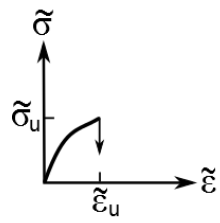

(d)

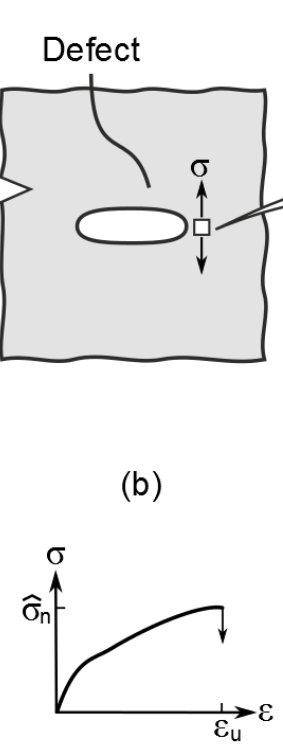

(e)

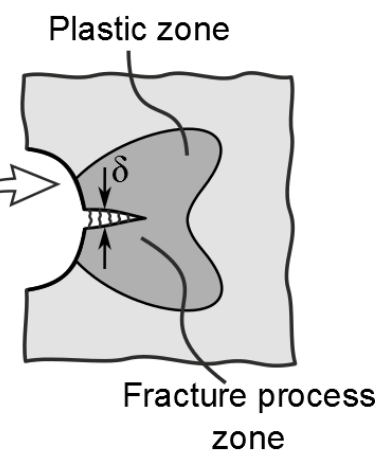

(c)

Fig. 1 Schematics of failure at macro-scale (a) and micro-scale with defects (b) and plasticity at the fracture process zone. Macro-scale stress-strain law (d), micro-scale stress-strain law (e), micro-scale traction-separation (cohesive) law (f)

On the micro-scale, however, the situation is very different. Here we will consider the material as heterogeneous, such as a composite consisting of discrete fibres in a matrix material that contains micro-scale defects (Fig. 1b). The stress and strain fields will be non-uniform, depending on micro-scale features. Failure will initiate from a pre-existing flaw. A pre-existing flaw, e.g. a pore (e.g. an air bubble) in a polymer material, will create a local stress concentration and multi-axial stress state at the vicinity of the pore (Fig. 1b) and a plastic zone can form around the fracture process zone (Fig. 1c), represented by a non-linear stress strain law. A fracture process zone will form when the stress at a pore reaches the micro-scale strength, denoted as $\hat{\sigma}_{n}$. The fracture process zone will develop into a micro-crack that will eventually grow into a macro-crack that will propagate across the entire cross-section of the specimen leading to macro-scale failure. At the instance when the fracture process zone begins to form, and the micro-scale stress at the pore is equal to $\sigma=\hat{\sigma}_{n}$, the associated strain is equal to the micro-scale failure strain, $\varepsilon_{u}$ (Fig. 1d). Once a fracture process zone has formed, its mechanical behaviour can be represented by a cohesive law (traction-separation law) as 
shown in Fig. 1f, i.e. $\sigma_{n}=\sigma_{n}\left(\delta_{n}\right)$, where $\delta_{n}$ is the normal opening displacement of the formed crack faces within the fracture process zone. The micro-scale strength, $\hat{\sigma}_{n}$, and the associated failure strain, $\varepsilon_{u}$, will be higher (Fig. 1e) than the associated macroscopic properties (Fig. 1d), $\hat{\sigma}_{n}>\tilde{\sigma}_{u}$ and $\varepsilon_{u}>\tilde{\varepsilon}_{u}$. An example of a determination of a complete micro-scale cohesive law, obtained by a J-integral approach based on the measurement of the end-opening, $\delta_{n}^{*}$, of a sharp pre-crack by high-resolution images obtained by ESEM experiments is given by Goutianos et al. [4].

In case we wish to make a micro-mechanical model of the experiment described above, it is obvious that we cannot use $\tilde{\sigma}_{u}$ as a local stress criterion for failure at the micro-scale. We need to know the local micro-scale strength $\hat{\sigma}_{n}$, and we must know the micro-scale stress-strain law in the entire strain range, $0<\varepsilon<\varepsilon_{u}$. It is thus the micro-scale failure strength and failure strain that should be used in micro-mechanical models. Therefore, in the present study, we aim to develop an approach to determine the micro-scale stress-strain law in the strain range beyond that obtainable from a traditional macroscopic tensile test, $\tilde{\varepsilon}_{u}<\varepsilon<\varepsilon_{u}$, and determine the micro-scale strength $\hat{\sigma}_{n}$.

In order to obtain the micro-mechanical properties of a polymer material, specimens with a finite notch root radii were made to mimic the stress state around a void. The specimens were subjected to double cantilever beam (DCB) tests in a vacuum chamber of an environmental scanning electron microscope (ESEM). From the images captured in the ESEM, the micro-scale strains around deformed notches were measured with the 2D digital image correlation (DIC) method using the commercial software ARAMIS [5]. The strain fields between the notches with initially different root radii were compared normalizing all length parameters with the width of deformed notch in accordance to McMeeking's numerical study [6].

\section{Theory}

\subsection{Strain field at the notch}

In order to characterize mechanical behaviour of a non-linear elastic polymer around the notches with finite root radii, the theory of non-linear fracture mechanics was used. The non-linear fracture mechanics, established by Hutchinson, Rice and Rosengren (HRR) [7,8], provide a unique measure of the crack tip fields for elastic-plastic materials within the context of a small strain deformation theory.

The non-linear stress-strain relationship is described in terms of the Ramberg-Osgood relation [9]

$\frac{\varepsilon}{\varepsilon_{o}}=\frac{\sigma}{\sigma_{o}}+\alpha\left(\frac{\sigma}{\sigma_{o}}\right)^{n}$

where $\sigma_{o}$ is the yield stress, $\varepsilon_{o}=\sigma_{o} / E$ is the elastic strain, $E$ is the Young's modulus, and $\alpha$ and $n$ are material constants. The strains around the crack tip in the HRR theory within the $J$ dominance region are given as [10]

$\varepsilon_{i j}=\alpha \varepsilon_{o}\left(\frac{J}{\alpha \sigma_{o} \varepsilon_{o} I_{n} r}\right)^{\frac{n}{n+1}} \bar{\varepsilon}_{i j}(\theta, n)$, 
where $\varepsilon_{i j}$ is the strain tensor, $J$ is the loading parameter, $\bar{\varepsilon}_{i j}(\theta, n)$ are the dimensionless functions and $I_{n}$ is the normalizing constant, which depends on the crack loading mode, on $n$, and on whether plane strain or plane stress state prevails [10]. The dimensionless functions $\bar{\varepsilon}_{i j}(\theta, n)$ are independent of $J$ and $r$ but depend on $n$ in the $J$ dominance region [10]. Therefore, the strain variations around the crack can be described as a product of two components. The first component controls the strain magnitude and the second component, $\bar{\varepsilon}_{i j}(\theta, n)$, gives the strain variations with an angle around the crack tip.

The stress intensity around the crack and notch under monotonic loading is described with a path-independent line integral $J$. The path-independence of the J-integral indicates that it can be determined around any contour encircling the tip of the crack and notch, $\Gamma$, in a counter clockwise direction as shown in Fig. 2 [10]. Along $\Gamma$ the J-integral can be determined as

$J=\int_{\Gamma} W d x_{2}-T_{i} \frac{\partial u_{i}}{\partial x_{1}} d s$

where $T_{i}$ is the traction vector acting on the contour $\Gamma, u_{i}$ is the displacement vector, $s$ is the arc length along $\Gamma, x_{1}=x$, and $x_{2}=y$. In (3), the Einstein summation rule is used. The strain energy density, $W$, is a function of the stress tensor, $\sigma_{i j}$, and the strain tensor, $\varepsilon_{i j}$,

$W=\int_{0}^{\varepsilon} \sigma_{i j} d \varepsilon_{i j}$

If $\Gamma$ is taken around the notch edge $\left(\Gamma=\Gamma_{\text {tip }}\right)$ as the blue dashed line in Fig. 2, then there are no tractions acting on the contour, i.e. $T_{i}=0$. According to Eq.3, now $J$ is only a function of $W$ and is given as [11]

$J_{t i p}=\int_{\Gamma_{t i p}} W d x_{2}$

Moreover, accordingly to the HRR theory $J$ is uniquely related to the crack tip opening, $\delta_{t}^{*}$, which is given as

$\delta_{t}^{*}=d_{n}\left(\alpha \varepsilon_{o}, \mathrm{n}\right) \mathrm{J} / \sigma_{\mathrm{o}}$

where the length parameter $d_{n}$ is ranging approximately from 0.3 for $n=3$ to 0.8 for large $n$ values with $\alpha=1$ $[10,12]$. Similar approach, as given in Eq.6, can be used to characterize the stress state in the front of notches with finite root radii. Numerically, McMeeking [6] found that the stress state in front of the notch depends on the ratio between the width of deformed notch, $\delta_{t}$, and the width of initial, i.e. undeformed, notch, $\delta_{t o}$, [6]

$\delta_{t} / \delta_{t o}=d_{n} J / \sigma_{0} \delta_{t o}$

The width of the deformed notch, $\delta_{t}$, is defined as the distance between the intercept of two $45^{\circ}$ lines drawn back from the tip in the deformed state as shown in Fig. 2. The same approach is used to measure the initial notch width in the un-deformed state denoted as $\delta_{t o}$.

McMeeking [6] also found that the stresses and strains around a notch can be describe in the same way as around smoothly blunting initially sharp cracks if all length parameters are normalized with the width of the deformed notch. Thus, the strain fields around the notch with smaller and larger notch root radii are the same 
in the normalized coordinate system. Numerical findings by McMeeking were both experimentally validated and used in data analysis.

\subsection{Determination of stress from strain energy density}

Eq. (5) can be expressed in polar coordinates using $d x_{2}=r \cos \theta d \theta, r=\delta_{t} / 2$, where $\delta_{t}$ is the width of the deformed notch, $r$ is the distance from the notch centre, and $\theta$ is an angle, see also Fig. 2 . Around the tractionfree surface of the notch $\left(r=\delta_{t} / 2\right)$, the only non-zero stress component is $\sigma_{\theta \theta}$ (the stress component in the circumferential direction). Then $W$ is the area under the $\sigma_{\theta \theta}-\varepsilon_{\theta \theta}$ stress-strain curve. According to Eq. (5), integrating around the notch, i.e. from $-\pi / 2$ to $\pi / 2$, it follows that the mean strain energy density, $\bar{W}$ (averaged around the notch) is

$J_{\text {tip }}=\bar{W} \delta_{t} \Rightarrow \bar{W}=J_{\text {tip }} / \delta_{t}$

Now the stress-strain relationship can be determined as follows. During the experiments, we recorded simultaneous values of $J, \varepsilon_{\theta \theta}$ and $\delta_{t}$. $(J$ was determined from specimen geometry and applied load level by evaluating the J-integral along the external boundaries, $J_{\text {ext }}$, see Section 3.4, and $\varepsilon_{\theta \theta}$ and $\delta_{t}$ were measured from ESEM images). Utilization of the path independence of the J-integral [11] gives that the J-integral evaluated around the notch, $J_{t i p}$, is the same as $J_{\text {ext }}$. Then by Eq. (8), we calculated the average strain energy density, $\bar{W}$. In the next step, $W$ (Eq. (4)) was extracted from the stress-strain relationships of power law hardening materials with various hardening exponents, $n$ ( $W$ denotes the area below the stress-strain curve). The experimental strain measurements around the notch were used to define the maximum value of the $\varepsilon_{\theta \theta}$ strain for the calculation of $W$. Then, the hardening exponent of the stress-strain law and failure stress of epoxy resin was found by matching $\bar{W}$, Eq. (8) with $W$, Eq. (4). This approach can be used for all load levels; we will use the approach only close to failure to assess the micro-scale failure strength $\hat{\sigma}_{n}$.

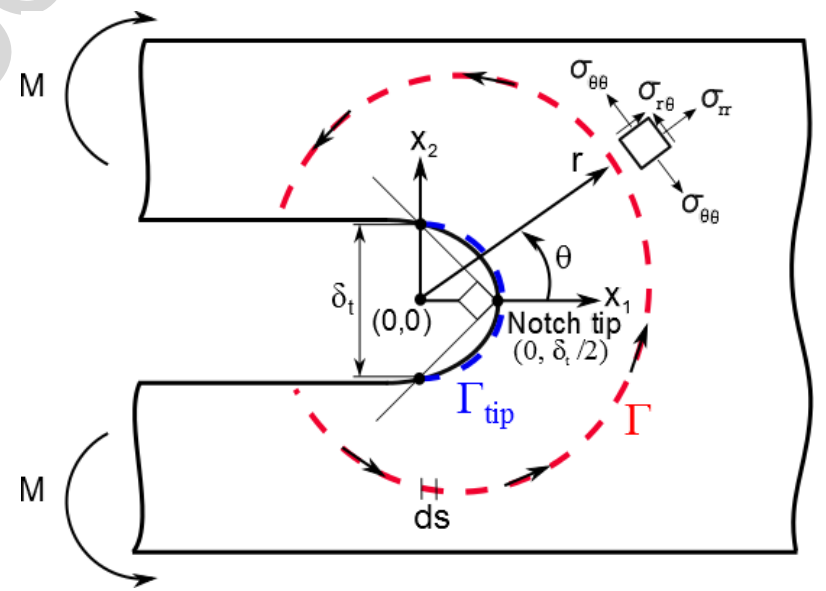

Fig. 2 Contours used for the J-integral determination

\subsection{Determination of stress from permanent strains}

An alternative way of finding the stress-strain law is to estimate the stress by the use of the strain value prior to unloading and the permanent strain, i.e. the strain recorded after unloading. We assumed that during 
unloading the elastic deformation is completely linear, and the slope of the unloading curve is identical to the slope of the stress-strain curve during loading in the elastic region as shown in Fig. 3.

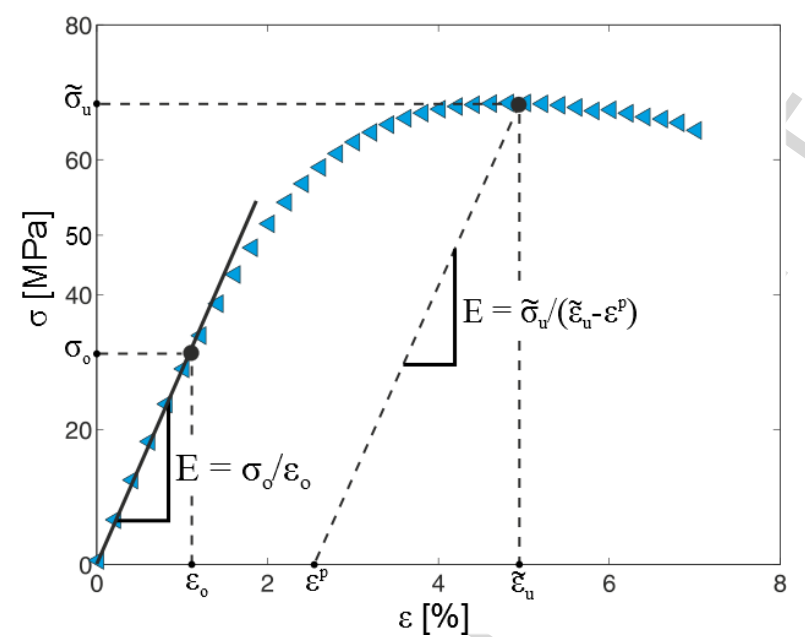

Fig. 3 The averaged macroscopic stress-strain curve in tension of the epoxy resin

Moreover, we expected that during re-loading the polymer will yield when the stresses at previous loading were reached. These assumptions were used to construct the stress-strain relation, i.e. knowing the strain values in loaded, $\varepsilon$, and unloaded state, $\varepsilon^{p}$, the stress, $\sigma$, was found from

$\sigma=E\left(\varepsilon-\varepsilon^{p}\right)$.

\section{Material and methods}

\subsection{The macro-mechanical properties of an epoxy resin}

The macro-mechanical properties of the polymer used in the present study, Airstone 760E epoxy, are briefly described below. The averaged macroscopic tensile curve is shown in Fig. 3. The material possesses certain ductility as the macro-scale failure strain, $\tilde{\varepsilon}_{u}$, reached $5 \%$ in tension and $6 \%$ in compression [13]. The corresponding maximum stress, $\tilde{\sigma}_{u}$, was measured to be $72 \mathrm{MPa}$ in tension and $86 \mathrm{MPa}$ in compression. Defining the yield at the point where the relationship between the tensile stress and strain deviates from the linearity, the yield stress, $\sigma_{o}$, was obtained of $32 \mathrm{MPa}$, the elastic strain, $\varepsilon_{o}$, of $1.12 \%$, and the elastic modulus, $E=\sigma_{o} / \varepsilon_{o}$, of $2.85 \mathrm{GPa}$. For more details, see the study by Zike and Mikkelsen [13].

\subsection{The design of specimens}

The micro-scale properties of the epoxy resin were measured by loading double cantilever beam (DCB) specimens by pure bending moments. The DCB specimen design was based on the previously conducted numerical parameter study [14]. In this study, the dimensions of the specimens were optimized in order to enable loading up to the onset of fracture within the fixture limitations [15]. 


\subsection{The specimen preparation}

\subsubsection{Manufacturing (Test Series 1 and Test Series 2)}

An epoxy resin Airstone 760E was mixed with a hardener Airstone (TM) 766H maintaining ratio 3:1. Further, the mixture was degassed in a vacuum chamber up to the vacuum of $98 \%$, what took approximately 5 minutes. After degassing, the liquid epoxy was poured into the mould consisting of two glass plates positioned parallel to each other with a distance equal to the specimen width as shown in Fig. 4b. In order to ensure that the liquid resin stays in the mould, a rubber pipe (red line in Fig. 4) between two glass plates was wrapped around three side edges. Clamping holders were used to fix the mould. In order to create notches with different radii, a sharp paper knife razor wrapped with an ETFE (ethylene tetrafluoroethylene) film with thickness of $12.7 \mu \mathrm{m}$ and PTFE (polytetrafluoroethylene) adhesive tape with thickness of $80 \mu \mathrm{m}$ was placed into an uncured epoxy. As a result, the specimens had an initial notch width of approximately $95 \mu \mathrm{m}$ and 245 $\mu \mathrm{m}$, denoted as Test Series 1 and Test Series 2, respectively. The epoxy was cured at $50^{\circ} \mathrm{C}$ for 5 hours. After cooling down to the room temperature, it was post-cured at $80^{\circ} \mathrm{C}$ for 3 hours.

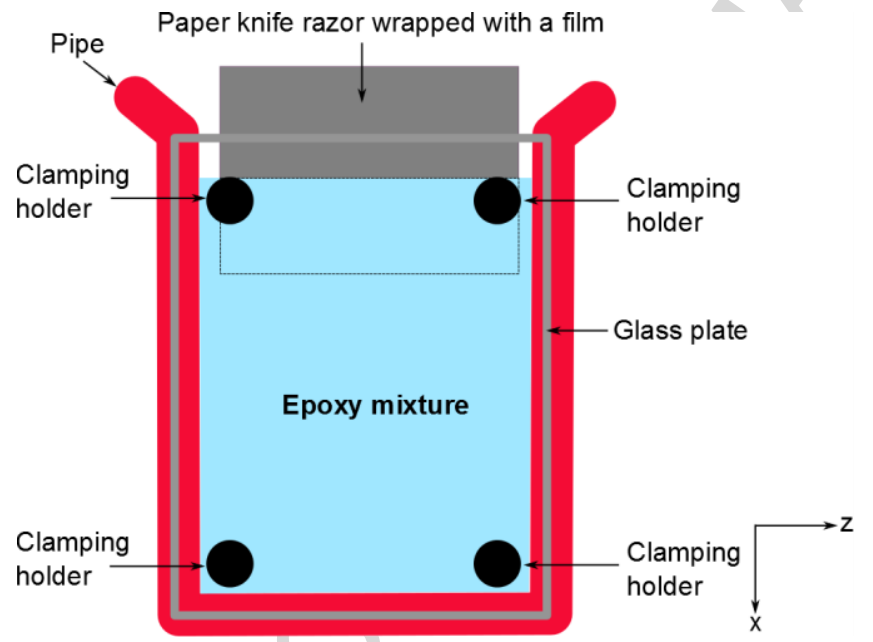

(a)

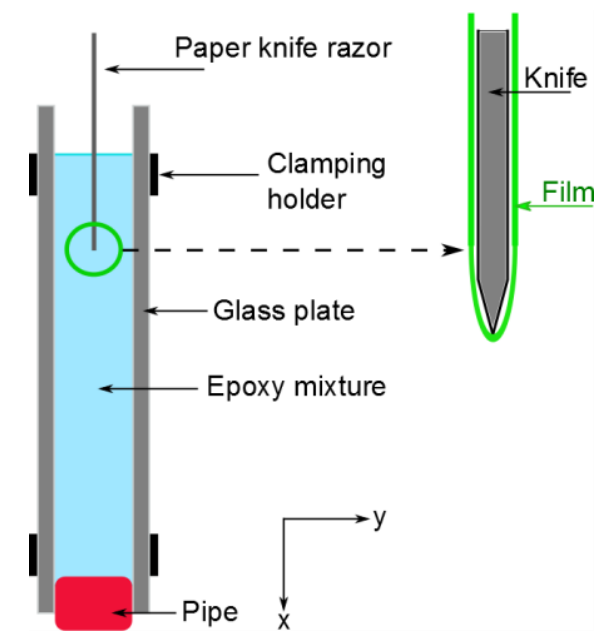

(b)

Fig. 4 Manufacturing of specimens in $x-z$ plane (a) and $x-y$ plane (b)

\subsubsection{Machining}

After post-curing, the paper knife razor was removed and the block of epoxy was cut into specimens with thickness of approximately $2.5 \mathrm{~mm}$. Holes with a radius of $1 \mathrm{~mm}$ were drilled at the end of the beams to create a "hook" for fixing the specimens within the DCB fixture [15]. In order to remove cutting defects and deep scratches around the notch, water cooled grinding of the front and back surface of the specimens was done utilizing a machine Struers LabPol 25. Sandpapers with a grit of 1000 and 4000 were used to grind off approximately $0.4 \mathrm{~mm}$ and $0.1 \mathrm{~mm}$, respectively, including the front and back surface. Additional polishing was done with a diamond paste with monocrystalline diameter of $1 \mu \mathrm{m}$ using a silk cloth to remove grinding scratches on the surface to be used for strain measurements. After machining, the specimens were kept at $80^{\circ} \mathrm{C}$ for one hour to remove residual stresses around the notches. The final dimensions are given in Fig. 5. 


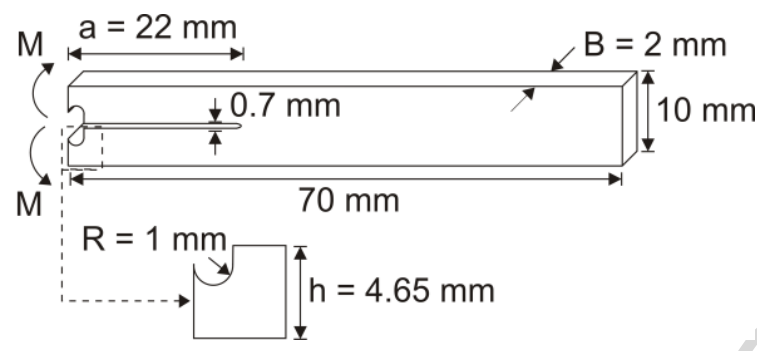

Fig. 5 The specimen dimensions

\subsubsection{Speckle sputtering}

Additional specimen surface preparation was done in order to utilize the digital image correlation (DIC) method for the strain measurements [16,17]. First, a gold layer with a thickness of $15 \mathrm{~nm}$ was sputtered onto the surface to be imaged. This was done to evaluate a surface smoothness before and after the test, since the speckle particles can be easily removed by immersing specimens in ethanol and applying ultrasound. In addition, gold layer gave a higher contrast for ESEM images later used for the digital image correlation method analysis. Next, speckles on the specimen surface were created by spraying solutions containing Tiand Fe- oxide particles. The solutions were created by dissolving $1 \mathrm{w} \%$ of Ti- and $5 \mathrm{w} \%$ of Fe- oxide particles in ethanol separately and stirred for approximately 2 hours with a magnetic mixer and mechanically with zirconia balls, respectively. The mean diameter of $\mathrm{TiO}_{2}$ and $\mathrm{FeO}$ particles was $0.5 \mu \mathrm{m}$ and $1.1 \mu \mathrm{m}$, respectively, and the total range of particle size was from 0.05 to $3 \mu \mathrm{m}$ according to the measurements by a laser diffraction particle size analyser Beckman Coulter LS 13320 [18]. The spraying was done with an airbrush BossDye-132 with a nozzle size of $0.3 \mathrm{~mm}$ [19].

\subsection{The DCB test procedure}

Micro-scale tests were performed with the DCB fixture specially designed by Sørensen et al. [15] for in-situ observations of failure mechanisms in an environmental scanning electron microscope (ESEM) ZEISS EVO 60 [20]. The loading fixture was equipped with a load cell with a capacity of $75 \mathrm{~N}$ (corresponding to a maximum moment of $6 \mathrm{Nm}$ ) and high precision linear displacement transducer $L D I$ 8/1 for load and opening measurements, respectively. The tests were performed step by step including loading-hold-unloading-hold procedure as shown in Fig. 6. Single test was divided into five steps with an applied moment values of 0.40 $\mathrm{Nm}, 0.56 \mathrm{Nm}, 0.80 \mathrm{Nm}, 0.96 \mathrm{Nm}$, and $1.20 \mathrm{Nm}$. Both loading and unloading were done with a rate in the range of $0.9-1.2 \mathrm{Nm} / \mathrm{min}$. The reason for conducting the unloading and hold was to study permanent strains and to capture images at different magnifications, respectively. During hold of approximately 4 min, the fixture displacement was fixed, and load drop up to $15 \%$ was observed. The highest load drop occurred for higher applied moments and was attributed to visco-elastic or visco-plastic deformation of the epoxy polymer. In the analysis of results, the load drop was neglected. 


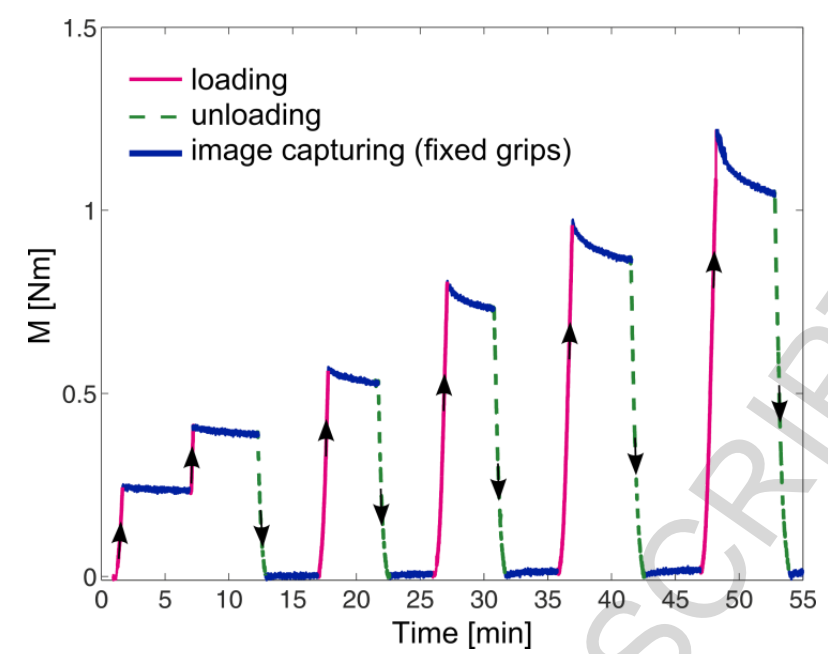

Fig. 6 A typical loading curve during the DCB test showing the applied moment versus time

In this study, the J-integral was considered as a loading parameter. Assuming that the material is macroscopically linear-elastic, the relation between $J$ and applied moment, $M$, for double cantilever beam specimens in plane stress was obtained by evaluating the J-integral along the external boundaries [21]

$J_{\text {ext }}=\frac{12 M^{2}}{B^{2} h^{3} E}$,

where $B$ and $h$ are the specimen dimensions presented in Fig. 4b. Fig. 7 shows that the actual specimens had small variations of the beam height close to the notch tip. For instance, the beam height was increasing from $h$ $=4.65 \mathrm{~mm}$ to $h=4.95 \mathrm{~mm}$ and to $h=4.88$ for the Test Series 1 and Test Series 2, respectively. The angled parts of the beams contribute to the J-integral, thus setting Eq. (11) equal to Eq. (8) is incorrect.

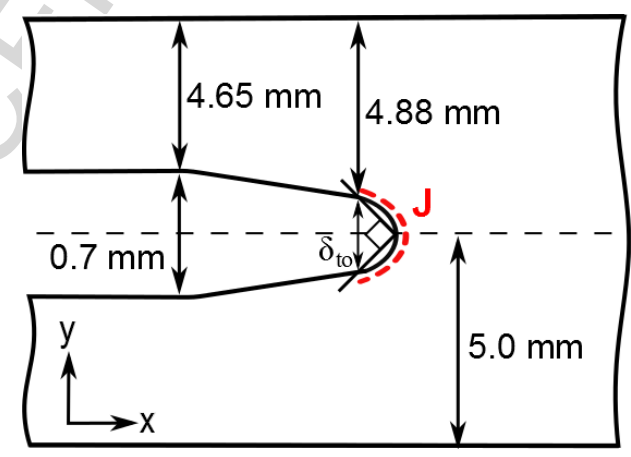

Fig. 7 The sketch of the actual notch (Test Series 2)

As a result, the evaluation of $J$ around the notch, $J_{\text {tip }}$, was done numerically [22]. The numerically estimated $J$ values around the notch for linear-elastic material under different applied moments are given in Table 1 .

Table 1 The numerically estimated $J$ values under different applied moments

\begin{tabular}{r|ccccc}
$M[\mathrm{Nm}]:$ & 1.20 & 0.96 & 0.80 & 0.56 & 0.40 \\
\hline$J\left[\mathrm{~kJ} / \mathrm{m}^{2}\right]$ (Test Series 1) & 12.7 & 7.2 & 4.9 & 2.4 & 1.1 \\
$J\left[\mathrm{~kJ} / \mathrm{m}^{2}\right]$ (Test Series 2) & 11.7 & 7.5 & 5.3 & 2.5 & 1.2
\end{tabular}

In the experiments, the loading beams were expected to behave elastically. In total, six specimens were tested, from which two correspond to Test Series 1 and four to Test Series 2. 


\subsection{Image capturing}

Inside the ESEM, images were captured under high vacuum of $6 \times 10^{-7}$ mbar using secondary electrons. The acceleration voltage was set to $8 \mathrm{kV}$, and the working distance was within the range of 12-14 mm. During each hold, images were captured at different magnifications as x100, x500, and x1000, i.e. magnification was altered during the test. This was possible as the microscope software allowed to set magnification with a decimal precision of 0.001 . In order to use images for the digital image correlation (DIC) analysis, it was important that the same view around the notch was maintained during the test. Thus, a specific point as a rigid particle on the surface for each magnification level was found and used to centre the image after each alteration of the magnification. The recording resolution, $N$, of the captured images was $1024 \mathrm{x} 768$ pixels $^{2}$, further the field of view, $l$, and the magnification factor, $M_{T}=N / l$, are listed in Table 2.

\subsection{DIC method}

From the images captured in the ESEM, the strains of the deformed specimen were measured with the 2D DIC method [16,17] using the commercial software ARAMIS v6.3.0 [5]. The images of specimen were divided into facets with a length of 45-60 pixels (facet size, $f$ ) and a distance between the centre points of the adjacent facets was set to 3-5 pixels (facet step, $p$ ). The facet size affects the displacement spatial resolution, $f / M_{T}$, and, in this study, it was within the range of $13 \mu \mathrm{m}$ to $177 \mu \mathrm{m}$ as shown in Table 2.

\begin{tabular}{cccccc}
\multicolumn{7}{c}{ Table 2 Parameters used to evaluate the DIC method } \\
$\begin{array}{c}\text { Magnifi- } \\
\text { cation }\end{array}$ & $\begin{array}{c}l \\
{\left[\mu \mathrm{m}^{2}\right]}\end{array}$ & $\begin{array}{c}M_{T} \\
{[\mathrm{pixel} / \mu \mathrm{m}]}\end{array}$ & $\begin{array}{c}f=60 \text { pixels }) \\
{[\mu \mathrm{m}]}\end{array}$ & $\begin{array}{c}f / M_{T} \\
(f=45 \text { pixels }) \\
{[\mu \mathrm{m}]}\end{array}$ & $\begin{array}{c}\text { Pixel } \\
\text { length } \\
{[\mu \mathrm{m}]}\end{array}$ \\
\hline $\mathrm{x} 100$ & $3000 \times 2250$ & 0.34 & 176.5 & 132.4 & 3.0 \\
x500 & $600 \times 450$ & 1.71 & 35.1 & 26.3 & 0.6 \\
x1000 & $300 \times 225$ & 3.41 & 17.6 & 13.2 & 0.3
\end{tabular}

During the DCB test, the specimen surfaces were undergoing brightness and contrast changes. Contrast changes were explained with the displacements in the $z$-axis direction (out-of-plane) dependent on an applied moment. The displacements were estimated in the range of 100-300 $\mu \mathrm{m}$, which were found to create artificial strain up to $0.42 \%$ for the strain components $\varepsilon_{\theta \theta}$ and $\varepsilon_{r r}$, and up to $1 \%$ for $\varepsilon_{e}$. The brightness, in-plane displacements, and imaging related distortions [23] were found to have a minor effect on the strain measurements, for more details see Appendix.

\subsection{Strain transformation}

Strains obtained from the ARAMIS software were measured in the Cartesian $(x-y-z)$ coordinate system. Since stress and strain fields around cracks and notches are commonly characterized using a polar coordinate system, a strain transformation was done as follows [24]

$$
\begin{aligned}
& \varepsilon_{\mathrm{rr}}=\varepsilon_{\mathrm{xx}} \cos ^{2} \theta+\varepsilon_{\mathrm{yy}} \sin ^{2} \theta+\varepsilon_{\mathrm{xy}} \sin 2 \theta, \\
& \varepsilon_{\theta \theta}=\varepsilon_{\mathrm{xx}} \sin ^{2} \theta+\varepsilon_{\mathrm{yy}} \cos ^{2} \theta-\varepsilon_{\mathrm{xy}} \sin 2 \theta, \\
& \varepsilon_{\mathrm{r} \theta}=\sin \theta \cos \theta\left(\varepsilon_{\mathrm{yy}}-\varepsilon_{\mathrm{xx}}\right)+\varepsilon_{\mathrm{xy}} \cos 2 \theta,
\end{aligned}
$$


where $\theta=\tan ^{-1}(y / x)$ and $x, y$ are point coordinates in the deformed state, when the centre point $(0,0)$ is set to $\delta_{t} / 2$ from the notch tip (see Fig. 2). Moreover, Eq. 12-14 were used to create a user defined visualization in the DIC software for the strain contour presentation. In this study, the effective von Mises strain, $\varepsilon_{e}$, which is a combination of different strain components, $\varepsilon_{i j}$, was as well included and given as

$\varepsilon_{e}=\sqrt{\frac{2}{3} \varepsilon_{i j} \varepsilon_{i j}}$

\section{Results}

\subsection{Determination of the micro-scale stress-strain relation and the failure stress}

\subsubsection{Estimation of stress-strain curve from strain energy density}

A specimen without an extensive amount of micro-cracks around the notch edge at the loading step close to failure was chosen and is shown in Fig. 8a. Close to failure $J$ reached $11.7 \mathrm{~kJ} / \mathrm{m}^{2}$ and the width of the deformed notch, $\delta_{t}$, was $346 \mu \mathrm{m}$. This gave $\bar{W}=33.8 \mathrm{MJ} / \mathrm{m}^{3}$ according to Eq. (8).

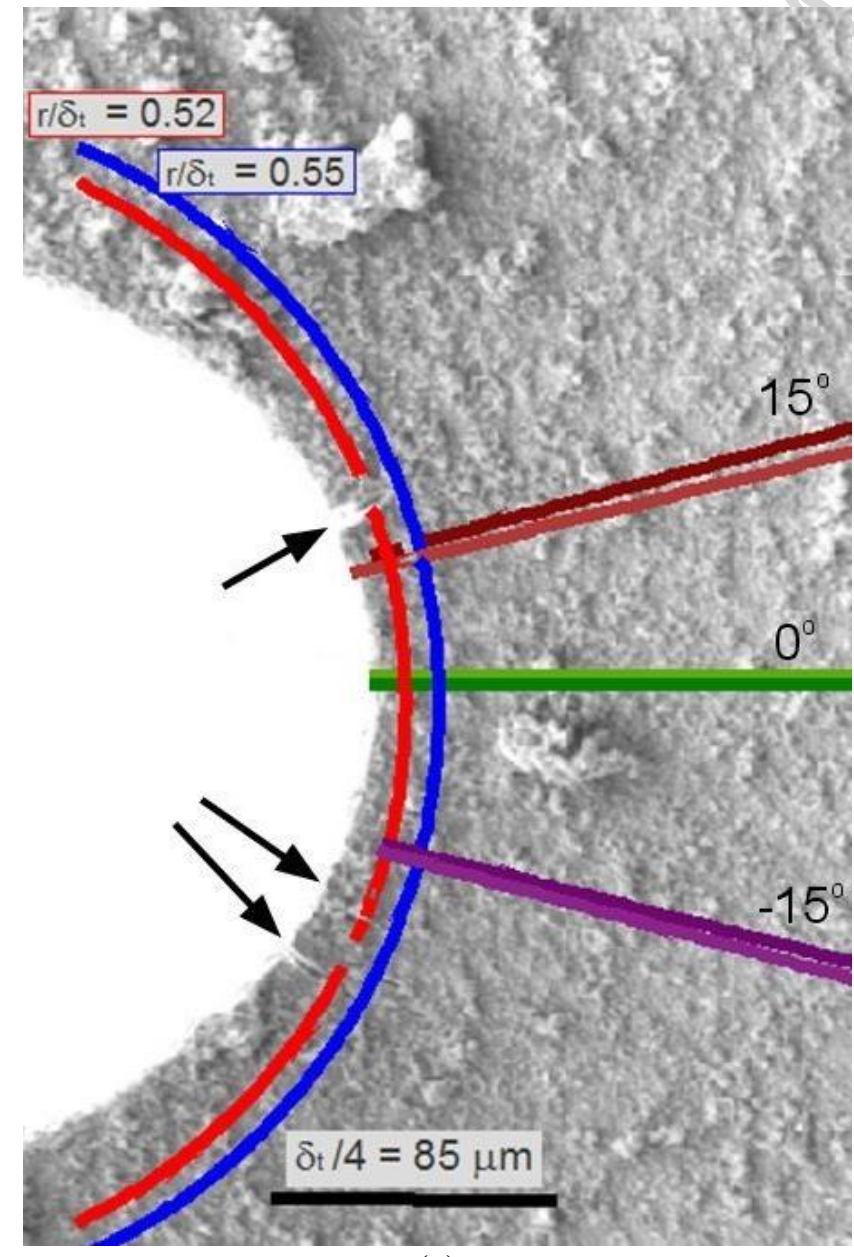

(a)

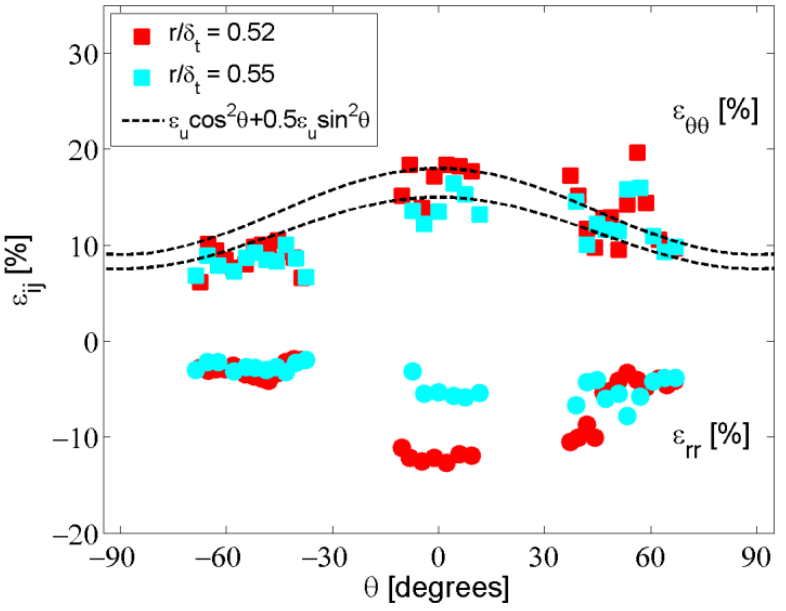

(b)

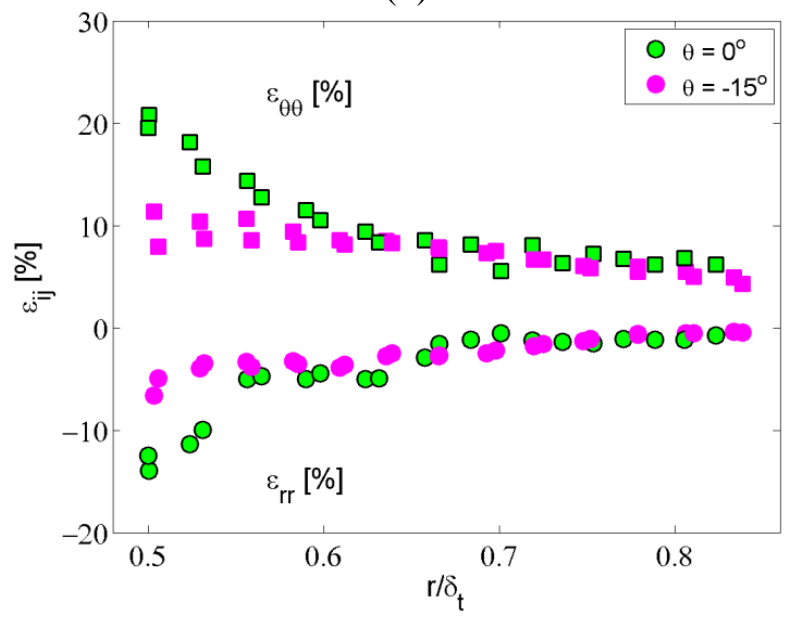

(c)

Fig. 8 The notch loaded with $J=11.7 \mathrm{~kJ} / \mathrm{m}^{2}$ and the corresponding strains along circumferential and radial paths (a). Microcracks are indicated by arrows. The associated strain components $\varepsilon_{\theta \theta}$ (squares) and $\varepsilon_{r r}$ (circles) are shown as a function of circumferential position (b) and as a function of radial position (c). 
Furthermore, the failure strain was measured around the same notch. These values were used to set the strain limit of the stress-strain curves used to extract $W$ values according to Eq. (4). In Fig. 8b the strains along circular paths with a normalized radius $r / \delta_{t}=0.52$ and $r / \delta_{t}=0.55$ and the distance from the notch edge of $7 \mu \mathrm{m}$ and $17 \mu \mathrm{m}$ are shown. From the acquired strain-angle curve it can be seen that the extreme values of $\varepsilon_{r r}$ and $\varepsilon_{\theta \theta}$ at $\theta=0^{\circ}$ reached $-13 \%$ and $17 \%$, respectively. The regions of missing data points were due to two largest material micro-cracks at $\theta \approx \pm 30^{\circ}$. Slightly larger absolute strain values were attained from the line paths starting just at the notch edge without incline as it is shown in Fig. 8c, where the extreme values of $\varepsilon_{r r}$ and $\varepsilon_{\theta \theta}$ reached $-15 \%$ and $20 \%$, respectively. The experiments indicated that the strain distribution around the notch is non-uniform and can be fitted to relation $\varepsilon_{u} \cos ^{2} \theta+0.5 \varepsilon_{u} \sin ^{2} \theta$ (Fig. 8b) [11], which gave the mean strain, $\bar{\varepsilon}$, of $15 \%$ for $\varepsilon_{u}=20 \%$.

Next, $W$ was determined according to Eq. (4) from the stress-strain curves presented in Fig. 9a, which were acquired fitting the macro-scale stress strain curve of the epoxy resin in tension (Fig. 3) to the RambergOsgood relation given in Eq. (1). The $W$ values, calculated using (4), for the stress-strain relations with the strain limits of $15 \%$ and $20 \%$ as a function of $n$ are shown in Fig. $9 \mathrm{~b}$. In addition, $\bar{W}$ is given as black dotted line. The power law exponent, $n$, was found at the point where $W$ agrees with $\bar{W}$. First, assuming that the strain around the notch is uniform and equal to the maximum strain of $20 \%$, gives $n=6$, and $\hat{\sigma}_{u} \approx 220 \mathrm{MPa}$. Second, considering a non-uniform strain distribution, thus taking the limiting strain value of $15 \%$, the material behaviour can be characterized as nearly elastic with $n<4$ and $\hat{\sigma}_{u}$ within the range of 450-580 MPa at $\varepsilon=20 \%$.

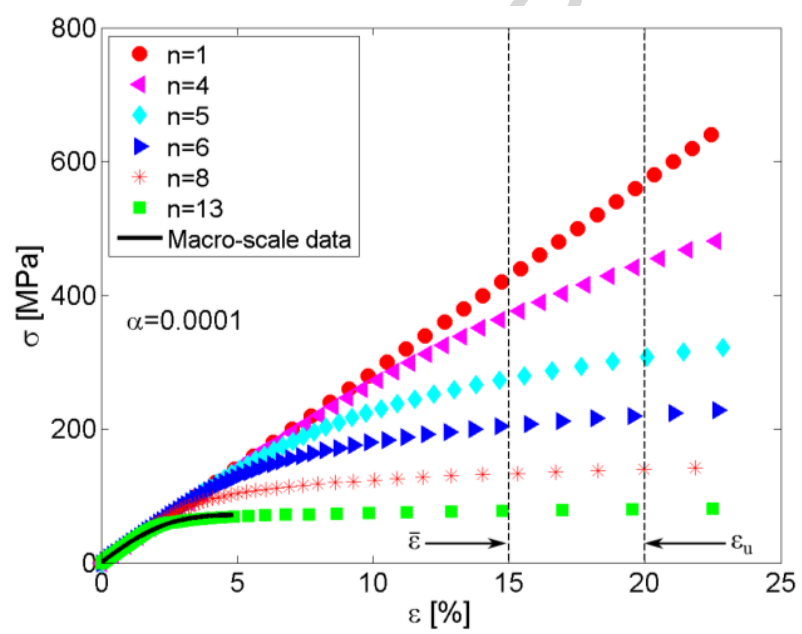

(a)

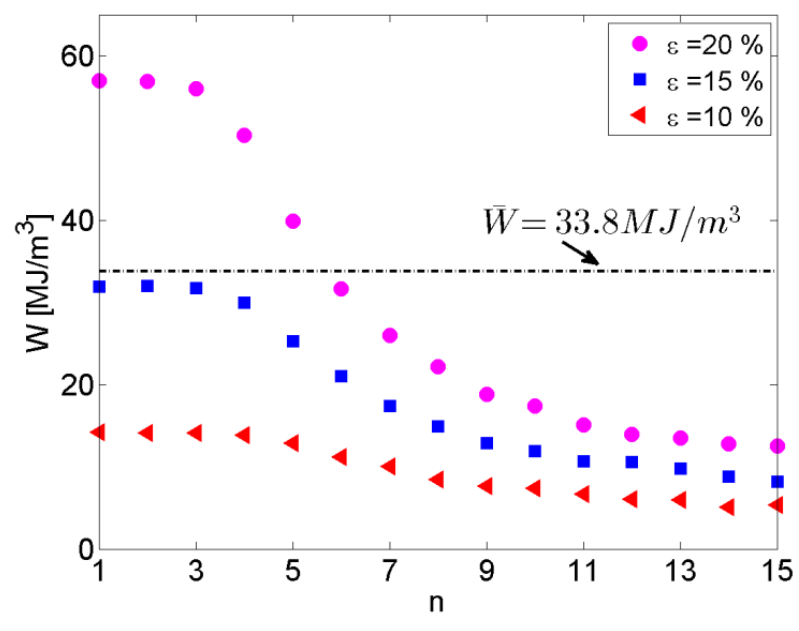

(b)

Fig. 9 The stress-strain relations with $n$ within the range of 1-13 for $\alpha=0.0001$ (a), and the strain energy density as a function of $n$ for strain limits of $10 \%, 15 \%$, and $20 \%$ (b)

In the similar way, the $n$ values were estimated for lower loading steps, i.e. applied $J<11.7 \mathrm{~kJ} / \mathrm{m}^{2}$, and are given in 
Table 3. At applied $J=7.5 \mathrm{~kJ} / \mathrm{m}^{2}, n$ was around 5, which was comparable to the results presented above. At lower load levels, i.e., for $J \leq 5.3 \mathrm{~kJ} / \mathrm{m}^{2}$, however, $\bar{W}$ and $W$ were not matching for any $n$ value. In addition, uncertainty of the strain measurements of approximately $1 \%$ was not found to affect results significantly.

Table 3 Extracted $n$ values for different applied $J$ (Test Series 2)

\begin{tabular}{|c|c|c|c|c|c|c|c|}
\hline \multirow{2}{*}{$\begin{array}{c}J_{a p p} \\
{\left[\mathrm{~kJ} / \mathrm{m}^{2}\right]}\end{array}$} & \multirow{2}{*}{$\begin{array}{c}J_{l o c} \\
{\left[\mathrm{~kJ} / \mathrm{m}^{2}\right]}\end{array}$} & \multirow{2}{*}{$\begin{array}{c}\delta_{t} \\
{[\mu \mathrm{m}]}\end{array}$} & \multirow{2}{*}{$\begin{array}{c}\bar{W} \\
{\left[\mathrm{MJ} / \mathrm{m}^{3}\right]}\end{array}$} & \multicolumn{2}{|c|}{$\begin{array}{r}\text { Uniform } \varepsilon \\
\left(\varepsilon=\varepsilon_{\max }\right)\end{array}$} & \multicolumn{2}{|c|}{$\begin{array}{l}\text { Non-uniform } \varepsilon \\
\qquad(\varepsilon=\bar{\varepsilon})\end{array}$} \\
\hline & & & & $\varepsilon_{\theta \theta}[\%]$ & $n$ & $\varepsilon_{\theta \theta}[\%]$ & $n$ \\
\hline 12.7 & 11.7 & 346 & 33.8 & $20 \pm 1$ & 6 & 15 & $<4$ \\
\hline 8.1 & 7.5 & 308 & 24.4 & $15 \pm 1$ & 5 & 11 & no fit \\
\hline 5.6 & 5.3 & 294 & 18.0 & $10 \pm 0.5$ & no fit & 7.5 & no fit \\
\hline
\end{tabular}

\subsubsection{Estimation of stress-strain curve from permanent strains}

During the DCB tests, the specimens were loaded up to certain $J$ and afterwards unloaded to $J=0 \mathrm{~kJ} / \mathrm{m}^{2}$. Then, as described in Section 2.3, an independent check can be made on the micro-scale stress-strain curve from the measured values of $\varepsilon_{e}$ and $\varepsilon_{e}^{p}$, using Eq. (9). Strain values, collected from a line paths drawn in front of the notch at $\theta=0^{\circ}$, are shown as points in Fig. 10 for two loading steps, i.e. for $J=5.3 \mathrm{~kJ} / \mathrm{m}^{2}$ (and the associated unloaded state) and $J=11.7 \mathrm{~kJ} / \mathrm{m}^{2}$. Additionally, the theoretical stress-strain curves with $n=1, n=$ 5, $n=6$, and $n=13$, also given in Fig. 9a, are included. In Fig. 10 it can be seen that the constructed stressstrain data points are displaced along the $\varepsilon_{e}$ axis respectively to the Ramberg-Osgood relations. Moreover, the constructed stress-strain data points acquired from different loading steps are almost not overlapping (red and green markers in Fig. 10). The reason could be artificial strain created by the out-of-plane displacements (see Appendix). For the strain component $\varepsilon_{e}$, the artificial strain of $1 \%$ was measured for the displacements along the $z$-axis of $300 \mu \mathrm{m}$. Moreover, the estimated stresses can be expected to be slightly overestimated. For instance, assuming that the permanent strains are unaffected by out-of-plane displacements, then the difference between $\varepsilon_{e}$ and $\varepsilon^{p}$ will increase by $1 \%$. According to Eq. (9), additional strain of $1 \%$ will rise the estimated stress by $30 \mathrm{MPa}$ for $E=3 \mathrm{GPa}$. Including the uncertainties, the epoxy resin seemed to be matching with the material models having $n=[5 ; 6]$. Similar stress-strain curve were constructed for the strain component $\varepsilon_{\theta \theta}$.

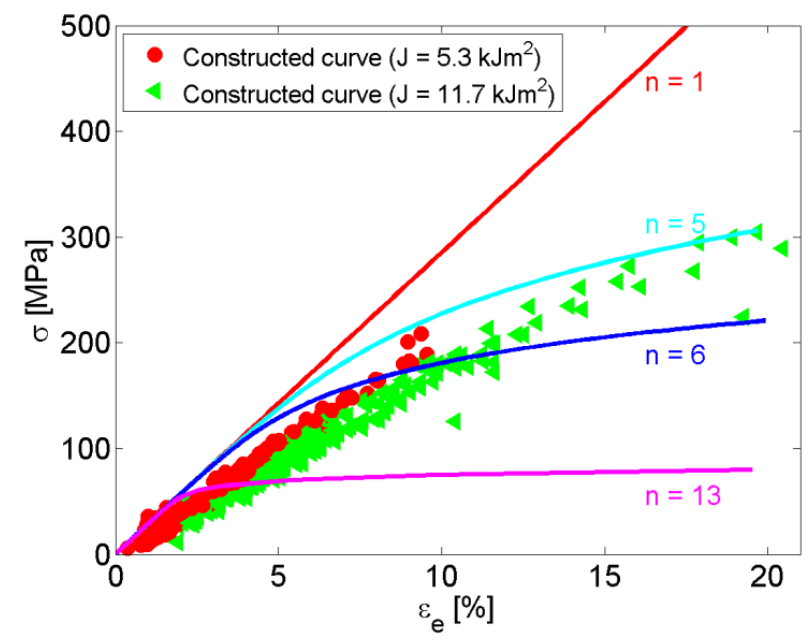

Fig. 10 The stress-strain curve constructed from the strains 


\subsection{Strain fields compared between notches with different notch root radius}

Below strain fields are compared between the Test series 1 and Test series 2 having an average initial notch width, $\delta_{t o}$, of $95 \mu \mathrm{m}$ and $245 \mu \mathrm{m}$, respectively. According to the analysis of McMeeking [6], the stress in front of the notch should depend on the ratio between the current and initial notch width, $\delta_{t} / \delta_{t o}$, which scales linearly with the normalized $J, J / \sigma_{o} \delta_{t o}$ (Eq. (7)). In order to test McMeeking's prediction, the normalized Jintegral versus normalized $\delta_{t}$ are presented in Fig. 11 for both test series.

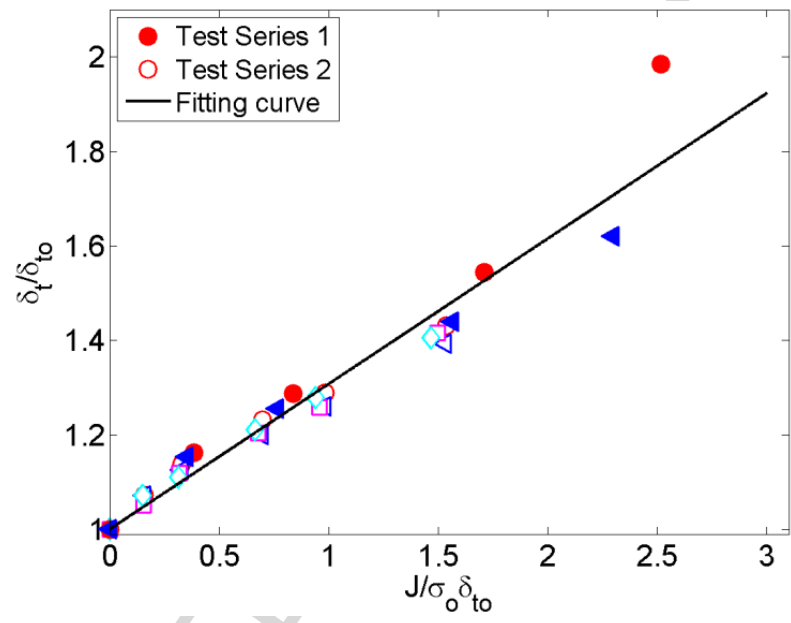

Fig. 11 The measured normalized notch width shown as a function of the normalized $J$ (load level). In total, 6 specimens are shown: 2 for Test Series 1 and 4 for Test Series 2

In Fig. 11 it can be seen that $\delta_{t} / \delta_{t o}$ varies linearly with $J / \sigma_{o} \delta_{t o}$ for both test series and tend to lie on the same curve $\left(d_{n}=0.3\right)$. This indicates that the relation between the normalized displacement and load can be considered independent of $\delta_{t o}$. Data points having the same $\delta_{t} / \delta_{t o}$ and $J / \sigma_{o} \delta_{t o}$ values between both test series were expected to have the same stress around the notch and were divided into Load Sets as given in Table 4.

Table 4 The load sets

\begin{tabular}{cccc} 
Load Set & $J / \sigma_{o} \delta_{t o}$ & $\begin{array}{c}\text { Test Series 1 } \\
J\left[\mathrm{~kJ} / \mathrm{m}^{2}\right]\end{array}$ & $\begin{array}{c}\text { Test Series 2 } \\
J\left[\mathrm{~kJ} / \mathrm{m}^{2}\right]\end{array}$ \\
\hline 1 & 0.45 & 1.1 & 2.5 \\
2 & 0.75 & 2.4 & 5.3 \\
3 & 1.60 & 4.9 & 11.7
\end{tabular}

For the same stress states, the strain fields of the two Test Series were expected to match if the length parameters normalized with $\delta_{t}$ [6]. For instance, in Fig. 12 and Fig. 13 the strain contour plots corresponding to the Load Set 2 are presented for the Test Series 1 ( $\boldsymbol{\Delta}$ in Fig. 11) and Test Series 2 ( $\Delta$ in Fig. 11), respectively. In order to illustrate the comparable length scales, square boxes with the edge length equal to $\delta_{t}$ were drawn in front of the notches. Since the notch width was greater for Test Series 2, the size of the box had to be larger for the Test Series 2 than Test Series 1. 

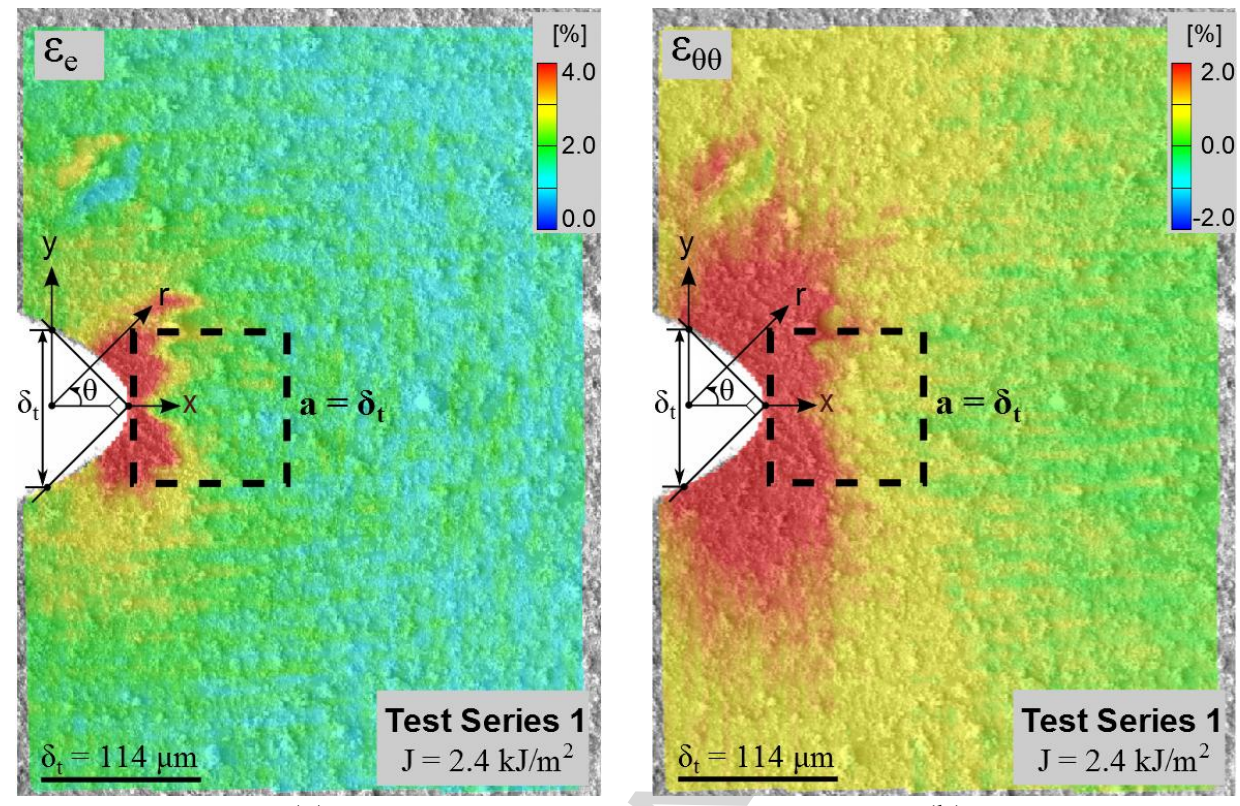

(a)

(b)

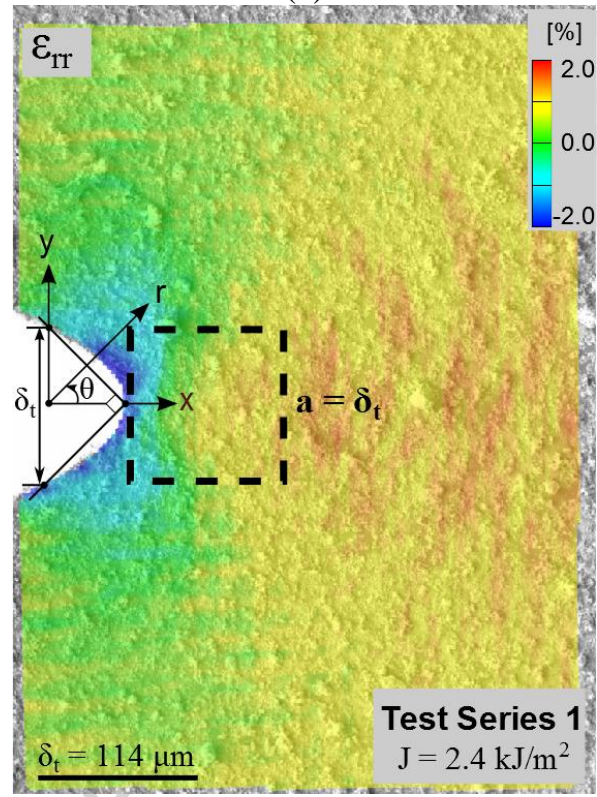

(c)

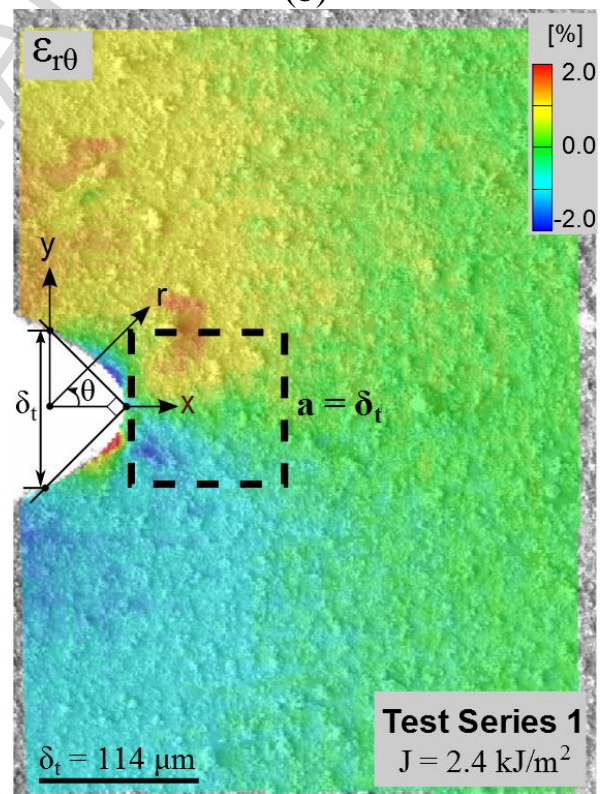

(d)

Fig. 12 The strain contour plots for the Test Series 1 at $J=2.4 \mathrm{~kJ} / \mathrm{m}^{2}$ (boxes indicate the comparable length scale with the Test Series 2, see Fig. 13) 


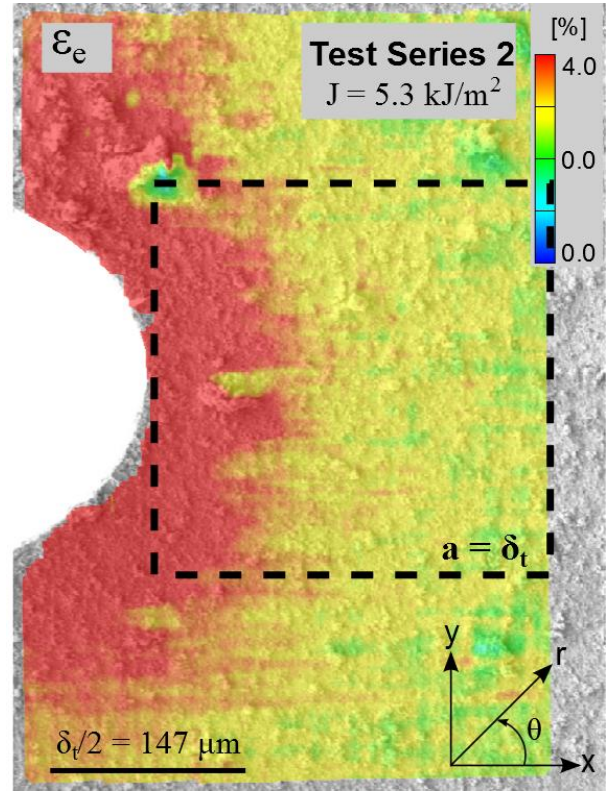

(a)

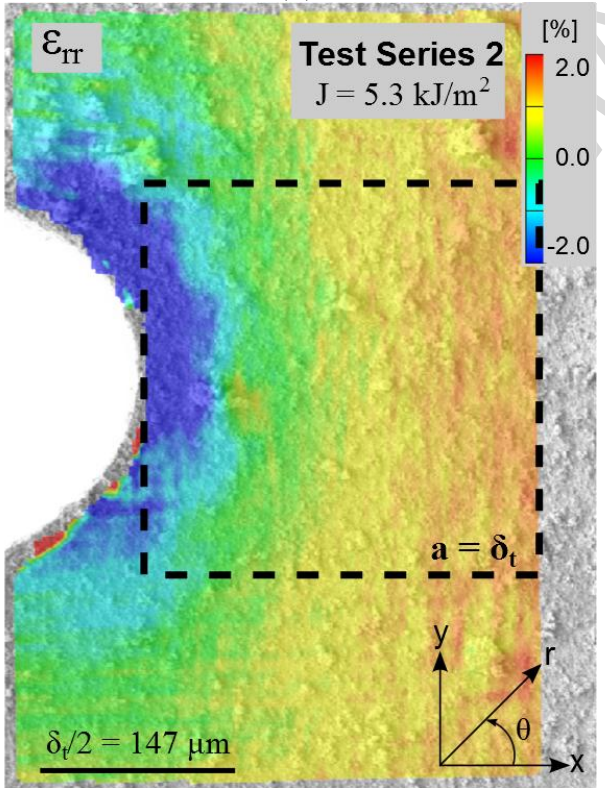

(c)

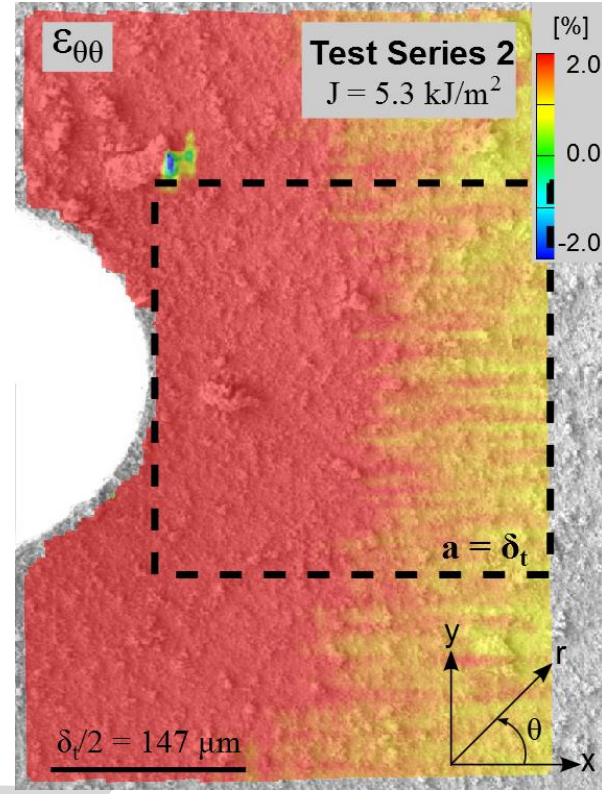

(b)

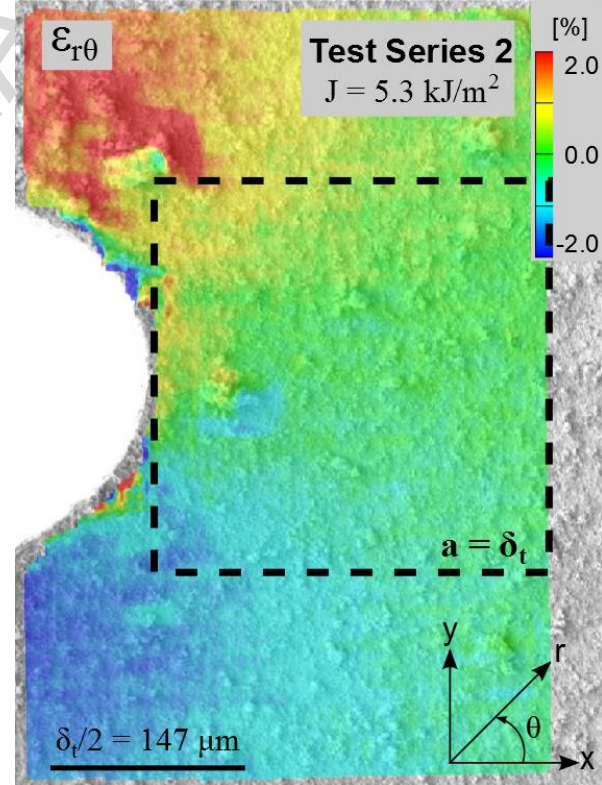

(d)

Fig. 13 The strain contour plots for the Test Series 2 at $J=5.3 \mathrm{~kJ} / \mathrm{m}^{2}$ (boxes indicate the

comparable length scale with the Test Series 1, see Fig. 12; the point of origin is out of view)

In order to show that strain fields in Fig. 12 and Fig. 13 are comparable, the strains were extracted along a circular path with a normalized radius from the notch centre $r / \delta_{t}=1$ for both test series at Load Set 2 and results are presented in Fig. 14. The strain fields between two test series seemed to have a rather good agreement, particularly for $\varepsilon_{r \theta}$ and $\varepsilon_{r r}$ (Fig. 14a). A small deviation of $1 \%$ was found for $\varepsilon_{\theta \theta}$, Fig. 14b, and slightly larger for $\varepsilon_{e}$ with a tendency to increase with an applied load, i.e. above Load Set 2. For instance, the values of $\varepsilon_{\theta \theta}$ and $\varepsilon_{e}$ appeared smaller for the Test Series 1 than for the Test Series 2 within the same Load Sets and at the same normalized distance. Moreover, the strain peaks of $\varepsilon_{\theta \theta}$ were less profound for the Test Series 2 as the strain drop at $\theta \approx 0^{\circ}$ was larger for the Test Series 1; and the angle corresponding 
to the maximum value of $\varepsilon_{\theta \theta}$ was slightly larger for the Test Series 2, e.g. the maximum strain peak appears at $\theta \approx 55^{\circ}$ for the Test Series 2 and at $\theta \approx 45^{\circ}$ for the Test Series 1 .

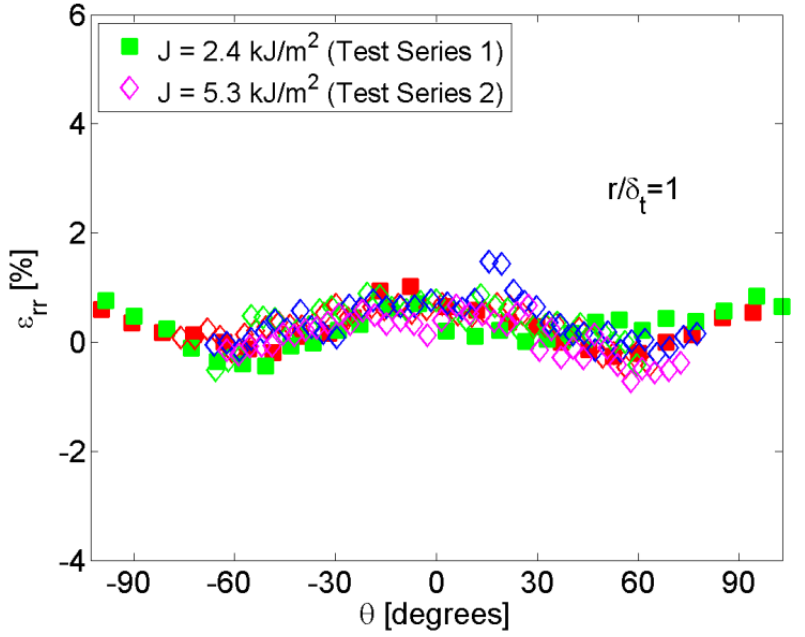

(a)

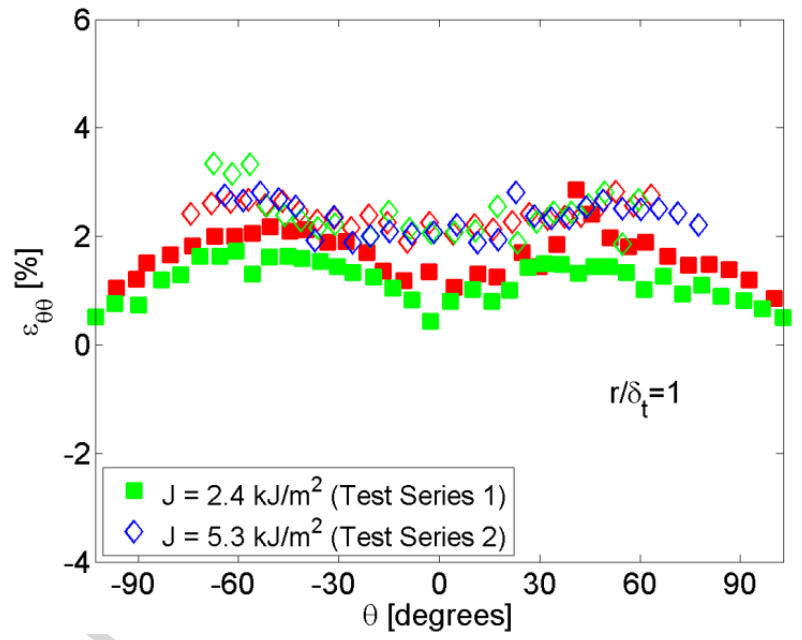

(b)

Fig. 14 The strain components $\varepsilon_{r r}$ (a) and $\varepsilon_{\theta \theta}$ (b) are the angle as a function of angle around the notch at $r / \delta_{t}=1(\operatorname{Load~Set~} 2)$. Filled markers correspond to the Test Series 1 and open markers to the Test Series 2. Different colours indicate different specimens within test series

\subsection{Strain field characterization}

\subsubsection{Global strain fields}

Contour plots of the strain fields around the deformed notch corresponding to the Test Series 1 are given in Fig. $15 \mathrm{a}-\mathrm{c}$ at $J \approx 5 \mathrm{~kJ} / \mathrm{m}^{2}$ recorded at magnification $\mathrm{x} 100$.

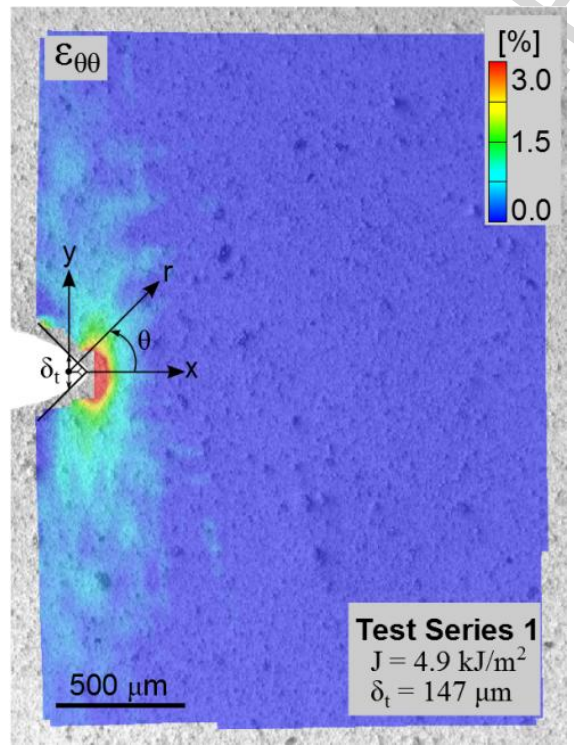

(a)

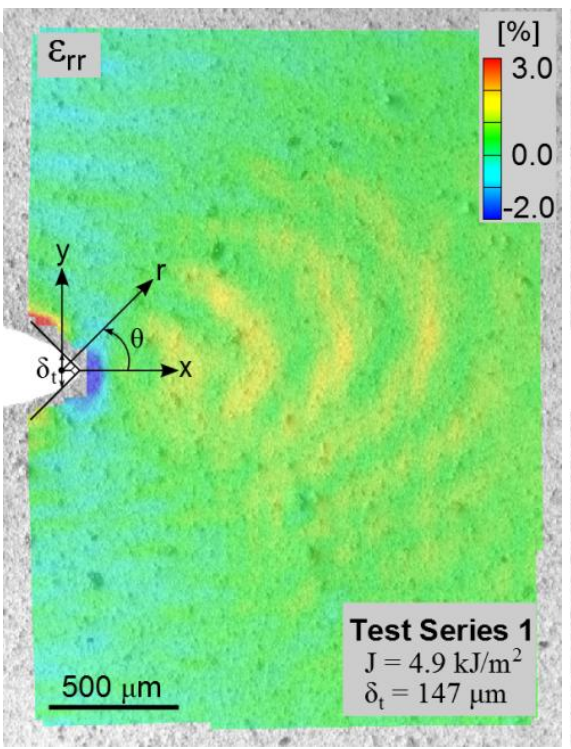

(b)

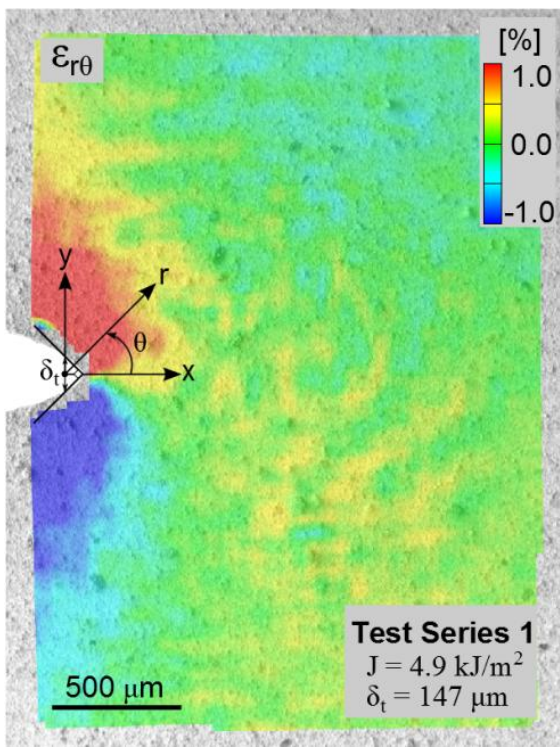

(c)

Fig. 15 The contour plots of $\varepsilon_{\theta \theta}(\mathrm{a}), \varepsilon_{r r}(\mathrm{~b})$, and $\varepsilon_{\theta r}(\mathrm{c})$ captured at magnification x100

In Fig. 15 it can be seen that $\varepsilon_{\theta \theta}$ (Fig. 15a) is positive and $\varepsilon_{r r}$ (Fig. 15b) is negative in the front of the notch tip. The value of the strain component $\varepsilon_{\theta \theta}$ was highest at the tip and decreased with increasing a distance from the notch, whereas the strain component $\varepsilon_{r r}$ had its lowest value (negative) in front of the notch and became positive with increasing the distance from the notch tip. A compressive region of $\varepsilon_{r r}$ diminished with an 
initiation of the central crack. Fig. 15c shows that the strain component $\varepsilon_{r \theta}$ was dominating around the notch edge sides and was asymmetric around the notch $(y=0)$. The strain fields for $\varepsilon_{r r}$ and $\varepsilon_{\theta \theta}$ were both symmetric about $y=0$ (Fig. 15a-b). Such symmetries are anticipated for the symmetric specimens loaded symmetrically. Similar strain distributions were measured for the Test Series 2 [22]. The contour plots in Fig. 15 have a greater field of view, but resolution, however, is low. For instance, observing the strain variations around the notch at the magnification of x500 (Fig. 12), the distribution of $\varepsilon_{e}, \varepsilon_{\theta \theta}$, and $\varepsilon_{r r}$ had a butterfly shape, which was hidden at the magnification x100 (Fig. 15). These differences are more discussed in Appendix.

\subsubsection{The strain variations with an angle around the notch at different normalized distances}

Fig. 16a shows the strain component $\varepsilon_{\theta \theta}$ as a function of the angle around the notch at different normalized distances $r / \delta_{t}$ (Test Series 1 with $\delta_{t}=104 \mu \mathrm{m}$ ) for $J=1.1 \mathrm{~kJ} / \mathrm{m}^{2}$. Data were acquired from a circular path drawn around the notch using images recorded at magnification x500. Results are presented for small applied $J$ to avoid the effect of the material micro-cracks evolving from the notch edge at higher loads. At the distance $r / \delta_{t}=0.8$, it can be seen that starting from $\theta=-90^{\circ}, \varepsilon_{\theta \theta}$ increases with $\theta$ until a maximum is attained at $\theta \approx$ $30^{\circ}$. After the maximum, the strain component $\varepsilon_{\theta \theta}$ declines and reaches minimum at $\theta=0^{\circ}$. The strain $\varepsilon_{\theta \theta}$ is symmetric about $\theta=0^{\circ}$, since the second maximum is at $\theta \approx 30^{\circ}$. Results show that the angle of the maximum $\varepsilon_{\theta \theta}$ value varies from $\theta \approx \pm 30^{\circ}$ at the distance $r / \delta_{t}=0.8$ to $\theta \approx \pm 60^{\circ}$ at $r / \delta_{t}=1.5$. Similar (not shown here) but less profound strain variations were also observed for the Test Series 2 , where the $\varepsilon_{\theta \theta}$ maxima were at $\theta \approx \pm 45^{\circ}$ at the normalized distance $r / \delta_{t}=0.8$ and approached $\theta \approx \pm 90^{\circ}$ at $r / \delta_{t}=3.0$.

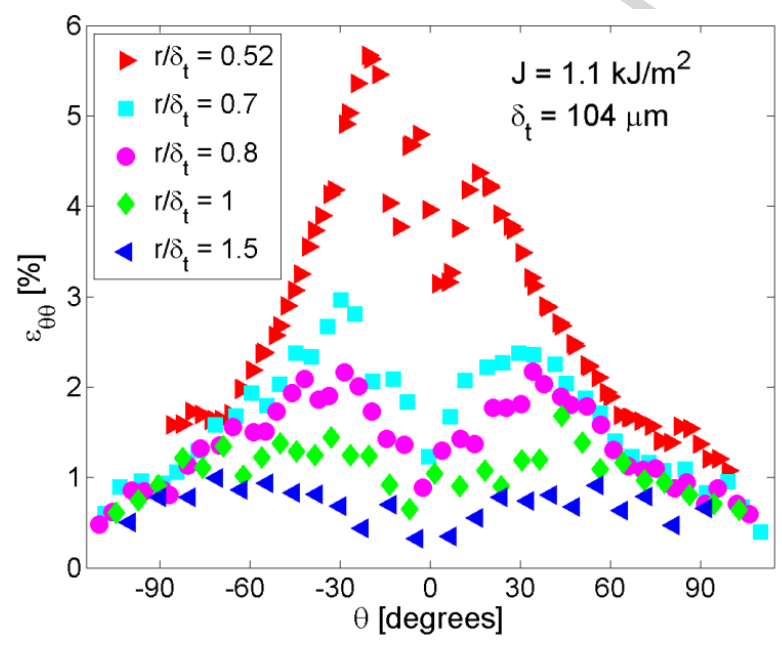

(a)

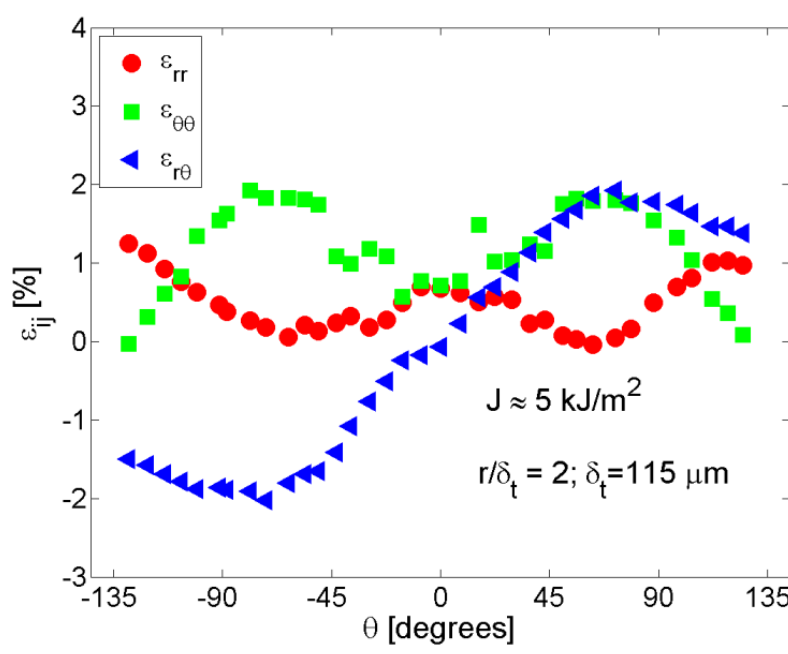

(b)

Fig. 16 The strain component $\varepsilon_{\theta \theta}$ is shown as a function of angle around the notch for various distances $r / \delta_{t}$ from the notch tip (a); the variations of all strain components with an angle around the notch at $r / \delta_{t}=2$ (b) (results for the Test Series 1)

The strain variations around the notch for all three strain components, i.e. $\varepsilon_{r r}, \varepsilon_{\theta \theta}$, and $\varepsilon_{r \theta}$, for $J \approx 5 \mathrm{~kJ} / \mathrm{m}^{2}$ at the normalized distance $r / \delta_{t}=2$ are shown in Fig. 16b (data attained at magnification x100). As it was apparent from the contour plots in Fig. 15, $\varepsilon_{r r}$ and $\varepsilon_{\theta \theta}$ are symmetric and $\varepsilon_{r \theta}$ asymmetric about $\theta=0^{\circ}$. Moreover, it follows from Fig. $16 \mathrm{~b}$ that the angle of the $\varepsilon_{\theta \theta}$ maximum coincides with the angle where $\varepsilon_{r r}$ has a minimum and vice versa. Thus, the angle of the minimum $\varepsilon_{r r}$ value varies similarly to the maximum $\varepsilon_{\theta \theta}$ value with 
various distances from the notch. The angle of the maximum and minimum value of $\varepsilon_{r \theta}$ changes with increasing the distance from the notch, i.e. at $r / \delta_{t}=0.7$ the strain peaks were observed at $\theta= \pm 20^{\circ}$ and at $r / \delta_{t}=$ 4 the angle increased up to $\theta= \pm 100^{\circ}$.

Moreover, the strain variations along the radial position $r / \delta_{t}$ at the fixed angle with an applied $J$ are acquired along line paths parallel $\left(\theta=0^{\circ}\right)$ to the $x$-axis. Fig. 17 shows $\varepsilon_{\theta \theta}$ and $\varepsilon_{r r}$ as a function of the normalized distance $r / \delta_{t}$ for $J$ within the range of $1.2-11.7 \mathrm{~kJ} / \mathrm{m}^{2}$. At the normalized distance $r / \delta_{t}<1$, the variations of $\varepsilon_{\theta \theta}$ became more distinct with an applied load approaching the strain values of 15-20\% (Fig. 17a). Slightly different observations were done for $\varepsilon_{r r}$ presented in Fig. 17b. In the vicinity of the notch edge, i.e. at $r / \delta_{t}=$ 0.5 , the strain component $\varepsilon_{r r}$ had negative values below $-10 \%$.

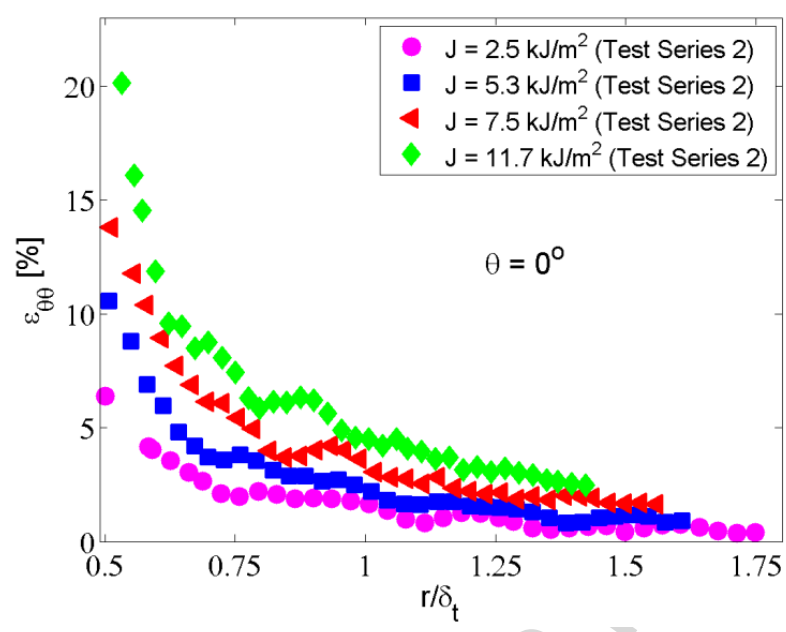

(a)

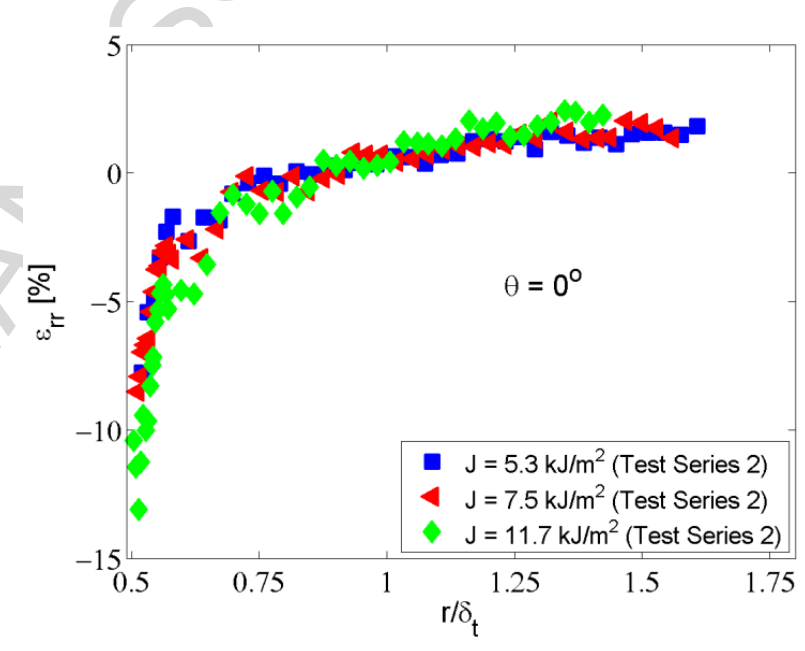

(b)

Fig. 17 The strains along the line paths at $\theta=0^{\circ}$ for $\varepsilon_{\theta \theta}(a)$ and $\varepsilon_{r r}(\mathrm{~b})$

\subsection{Formation of microcracks and macrocracks}

A general overview of principal features of crack initiation is given below. Performing the DCB test without speckles a few small fine cracks both parallel and inclined respectively to the $x$-axis were observed in the front of the notch at relatively low applied $J\left(J<2.4 \mathrm{~kJ} / \mathrm{m}^{2}\right)$. The density of these micro-cracks increased with a greater load. Accordingly to Bradley [25], the formation of these fine micro-cracks is related to the gold coating cracking caused by increasing deformation in the material below the coating. For instance, in Fig. 18ab multiple fine cracks next to the severely damaged notch with a central crack are shown at two different magnifications. From the image captured at lower magnification (Fig. 18b), it is apparent that the net of fine cracks continued even beyond the central crack indicating the size of the region of non-linear material deformation [25]. In Fig. 18 the specimens were initially tested with speckles, which were afterwards removed with ultrasound, thus the dark and white spots visible in Fig. 18 are related to the peeled off gold coating and remaining of speckles, respectively.

For applied $J>2.4 \mathrm{~kJ} / \mathrm{m}^{2}$, fine gold coating micro-cracks proceeded to formation of micro-cracks in the polymer material as shown in Fig. 18a. Like the gold coating cracks, these material micro-cracks appeared as surface openings both parallel and inclined respectively to the $x$-axis, but were deeper and wider. The micro- 
cracks in the polymer material tended to appear at the sides of the notch edge at the mean angle of $33 \pm 7^{\circ}$ respectively to the notch centre and were mostly around $25 \mu \mathrm{m}$ long. Up to the failure initiation, the material micro-cracks extended with an applied moment, but became still with a formation of the central crack. For instance, in Fig. 18a an inclined material micro-crack close to the notch tip can be observed, which initiated at $J \approx 2.4 \mathrm{~kJ} / \mathrm{m}^{2}$ but stopped to grow further as a central crack formed at $J \approx 5 \mathrm{~kJ} / \mathrm{m}^{2}$. The appearance of the central crack was found to indicate the failure initiation of the polymer material. The specimens from the Test Series 1 failed at the mean $J=8.5 \pm 0.4 \mathrm{~kJ} / \mathrm{m}^{2}$, whereas specimens from the Test Series 2 were not tested up to failure due to restricted displacement of the fixture.

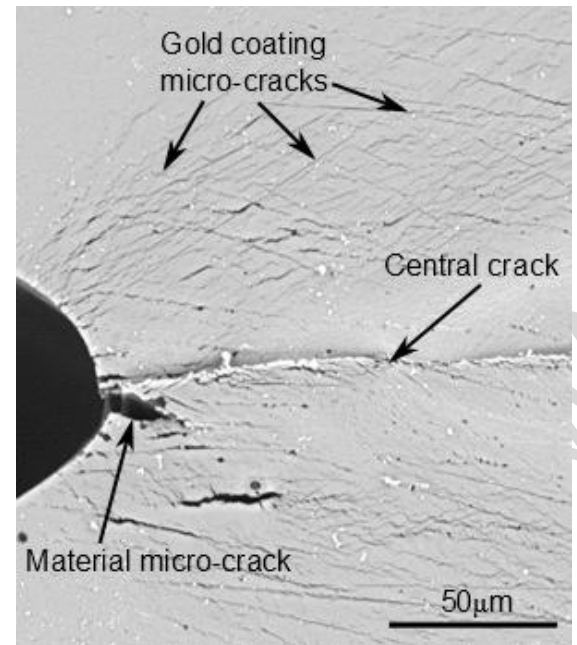

(a)

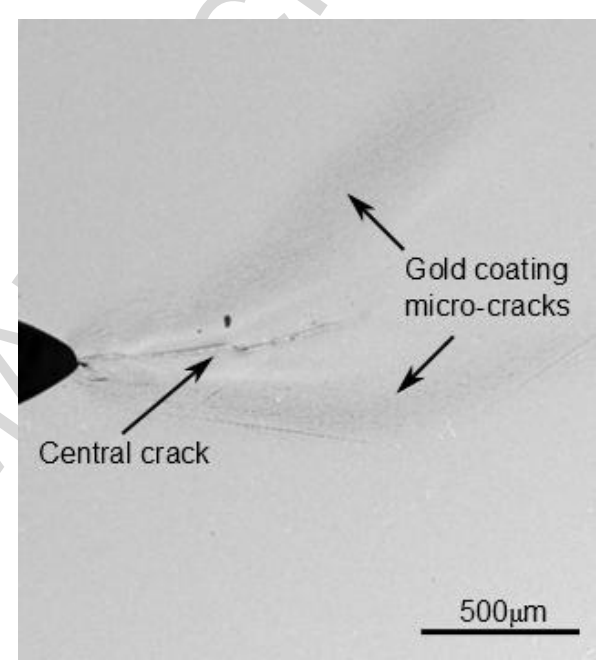

(b)

Fig. 18 The damaged surface around the notch without speckles for the Test Series 1 in the unloaded state after applied $J=7.2 \mathrm{~kJ} / \mathrm{m}^{2}$ at magnification $\times 1000$ (a) and $\times 100$ (b)

\section{Discussion}

\section{The micro-mechanical properties of the epoxy resin}

Our measurements confirm the expectations that at the micro-scale the failure strain and stress are significantly larger than the failure strain and stress at the macro-scale. The micro-scale measurements showed that just prior to failure initiation the strain components $\varepsilon_{\theta \theta}$ and $\varepsilon_{r r}$ reach $20 \%$ and $-15 \%$ at the notch edge, respectively. The micro-scale failure stress, $\hat{\sigma}_{n}$, was estimated in the range of 220-300 MPa employing analytical and empirical approaches.

Empirically, the stress-strain data constructed by the use of the permanent strain were related with the power law hardening material with $n=[5 ; 6]$, which gave $\hat{\sigma}_{n}$ within the range of 220-300 MPa. Some deviations were observed comparing the constructed stress-strain curves with the Ramberg-Osgood relations. Partly, they can be explained with the out-of-plane displacements during the experiments and possibly non-linear unloading. An out-of-plane displacement of $300 \mu \mathrm{m}$ creates artificial strain of $1 \%$ for the strain component $\varepsilon_{e}$. As a result, this translates the constructed stress-strain data along the $\varepsilon_{e}$ axis in Fig. 10. A measurement error of $1 \%$ would give a $30 \mathrm{MPa}$ increase in the estimated stresses (Eq. 9). Additionally, it has been reported [26] that the epoxy resin possesses some non-linearity during unloading. Since the stiffness tends to decline during 
unloading, the stresses constructed by the use of a linear stress-strain curve for unloading could be overestimated. The failure stress values, however, are still expected to be in the range given above.

This empirical approach showed agreement with the analytical approach where the stress-strain curve was attained employing different methods of extracting strain energy density, particularly, when the strain around notch edge was assumed to be uniform and equal to the maximum value. The limitation of the analytical approach, however, is that the strains were measured on the surface of specimens, and strain distribution through the thickness was unknown. That is, $\bar{W}$ an average strain energy density around the notch (Eq. 8) was compared to the $W$ (Eq. 4) extracted from the Ramember-Osgood relations setting the strain limit accordingly to the measurements on the upper surface of the deformed notch. In the thickness direction, it is expected that the strain values will increase, thus an average strain around the notch will be higher than considered in this study.

\section{Characterization of the strain fields around the notch}

According to the HRR theory $[7,8]$, the strain around the crack tip can be described as a product of two parts (Eq. 2). The first part is related to the magnitude of $J$, and the second, $\bar{\varepsilon}_{i j}$, to the strain variations with the angular position around the notch. The function $\bar{\varepsilon}_{i j}$ was expected to be independent of both the distance from the crack tip, $r$, and applied loading $J$ if the HRR region prevails. Moreover, we assumed that the strain fields around the notch can be described in the same way as around the sharp crack if the length parameters are normalized with $\delta_{t}$ [6]. In our experimental results, the strain variations with an angle were found to change with a distance from the notch centre, e.g. the maximum of $\varepsilon_{\theta \theta}$ translated from $\theta= \pm 30^{\circ}$ at $r / \delta_{t}=0.6$ to $\theta=$ $\pm 90^{\circ}$ at $r / \delta_{t}=4$, and $-\varepsilon_{r r}=\varepsilon_{\theta \theta}$. Likewise, changed $\varepsilon_{r \theta}$ reaching the largest angle of the strain maximum of $\theta \approx$ $90^{\circ}$ at $r / \delta_{t}=4$. At the notch edge, the strain component $\varepsilon_{\theta \theta}$ was dominating, whereas for $r / \delta_{t}>2$ the strain components $\varepsilon_{\theta \theta}, \varepsilon_{r r}$, and $\varepsilon_{r \theta}$ showed similar amplitude. Our results seem to deviate from those numerically derived by Hutchinson [27] using the HRR theory. Some discrepancies can be expected to be due to the notch geometry as it was not entirely semi-circular. Other reason can be that the evolution of the strain fields in the plastic zone was not uniquely controlled by the HRR field. This can be the case if the assumption of a small plastic zone (in comparison with specimen dimensions) is not met. This was probably the main reason in our case where the height of the DCB beams $H$ was only by factor 20-50 larger than the notch root radius.

\section{Conclusions}

The micro-scale failure stress and failure strain of the epoxy resin were found to be higher than the macroscale failure stress. In our micro-mechanical study, the failure strain reached $20 \%$ at the notch edge with the corresponding failure stress within the range of 220-300 MPa. This gives that the strength of the epoxy resin at the micro-scale is about 3 to 4 times larger than the strength at the macro-scale. Therefore, the use of the macroscopic stress-strain relation in micro-mechanical models is insufficient. It is the micro-scale stress-strain law that should be used in micro-mechanical models, e.g. as stress-strain law and micro-scale tractionseparation law in a cohesive law representing material fracture. 
Moreover, the strain fields of the specimens with dissimilar initial notch root radii were found comparable under moderate loadings. In line with the model prediction of McMeeking, we found that to obtain comparable strain fields, the length parameters have to be normalized with the current width of the notch, $\delta_{t}$.

\section{Acknowledgments}

This research was supported by the Danish Centre for Composite Structure and Materials for Wind Turbines (DCCSM), grant no. 09-067212, from the Danish Strategic Research Council (DSF). The authors would like to thank Christian H. Madsen and Erik Vogeley for assistance with specimen preparation and the test set up.

\section{References}

[1] P. Brøndsted, H. Lilholt, A. Lystrup, COMPOSITE MATERIALS FOR WIND POWER TURBINE BLADES, Annu. Rev. Mater. Res. 35 (2005) 505-538.

[2] B.F. Sørensen, J.W. Holmes, P. Brøndsted, K. Branner, Blade materials, testing methods and structural design, in: Wind Power Gener. Wind Turbine Des., WIT press, 2010: pp. 417-466.

[3] L.E. Asp, L.A. Berglund, P. Gudmundson, Effects of a composite-like stress state on the fracture of epoxies, Compos. Sci. Technol. 53 (1995) 27-37.

[4] S. Goutianos, R. Arevalo, B.F. Sørensen, T. Peijs, Effect of Processing Conditions on Fracture Resistance and Cohesive Laws of Binderfree All-Cellulose Composites, Appl. Compos. Mater. 21 (2014) 805-825.

[5] GOM, ARAMIS software, (n.d.). http://www.gom.com/3d-software/aramis-software.html.

[6] R.M. McMeeking, Finite deformation analysis of crack-tip opening in elastic-plastic materials and implications for fracture, J. Mech. Phys. Solids. 25 (1977) 357-381.

[7] J.W. Hutchinson, Plastic stress and strain fields at a crack tip, J. Mech. Phys. Solids. 16 (1968) 337-342.

[8] J.R. Rice, G.F. Rosengren, Plane strain deformation near a crack tip in a power-law hardening material, J. Mech. Phys. Solids. 16 (1968) 1-12.

[9] W. Ramberg, W.R. Osgood, Description of stress-strain curves by three parameters, Natl. Advis. Comm. Aeronaut. (1943).

[10] J.W. Hutchinson, Fundamentals of the phenomenological theory of nonlinear fracture mechanics, J. Appl. Mech. 50 (1983) 1042-1051.

[11] J. Rice, A path independent integral and the approximate analysis of strain concentration by notches and cracks, 35 (1967) 379-386.

[12] C.F. Shih, Relationships between the J-integral and the crack opening displacement for stationary and extending cracks, J. Mech. Phys. Solids. 29 (1981) 305-326.

[13] S. Zike, L.P. Mikkelsen, Mechanical characterization of the epoxy polymer matrix with an application to pressure dependent material model, Submitt. to Exp. Mech. (n.d.).

[14] S. Zike, B.F. Sørensen, L.P. Mikkelsen, DCB Test Sample Design for Micro-Mechanical Testing, in: 19th Int. Conf. Compos. Mater. (ICCM 19), Montreal, 2013.

[15] B.F. Sørensen, A. Horsewell, O. Jørgensen, A.N. Kumar, P. Engbæk, Fracture resistance measurement method for in situ observation of crack mechanisms, J. Am. Ceram. Soc. 81 (1998) 661-669.

[16] B. Pan, K. Qian, H. Xie, A. Asundi, Two-dimensional digital image correlation for in-plane displacement and strain measurement: a review, Meas. Sci. Technol. 20 (2009) 062001.

[17] M.A. Sutton, J.J. Orteu, H.W. Schreier, Image Correlation for Shape, Motion and Deformation MeasurementsBasic Concepts, Theory and Applications, 2009.

[18] Beckman Coulter, Laser diffraction particle size analyzer, (n.d.). https://www.beckmancoulter.com/wsrportal/wsr/industrial/products/laser-diffraction-particle-size-analyzers (accessed April 28, 2015).

[19] Airbrush BossDye-132, (n.d.). http://www.co-import.dk/16350228.

[20] ZEISS, Environmental scanning microscope, electron (n.d.). http://www.zeiss.com/microscopy/en_de/products/scanning-electron-microscopes/evo-materials.html.

[21] T.L. Anderson, Fracture Mechanics: Fundamentals and Applications, 1995.

[22] S. Zike, Micro-Scale Experiments and Models for Composite Materials with Materials Research (Thesis), Technical University of Denmark, 2015.

[23] M.A. Sutton, N. Li, D. Garcia, N. Cornille, J.J. Orteu, S.R. McNeill, et al., Metrology in a scanning electron microscope: theoretical developments and experimental validation, Meas. Sci. Technol. 17 (2006) 2613-2622.

[24] F.P. Beer, R.E. Johnston, Transformations of stress and strain, in: Mech. Mater., McGraw-Hill Book Company, 1992: pp. 339-400. 
[25] W.L. BRADLEY, Chapter 5 - Relationship of Matrix Toughness to Interlaminar Fracture Toughness, in: Appl. Fract. Mech. to Compos. Mater., 1989: pp. 159-187.

[26] H.S. Da Costa Mattos, S.D.A. Martins, Plastic behaviour of an epoxy polymer under cyclic tension, Polym. Test. 32 (2013) 1-8.

[27] J.W. Hutchinson, Nonlinear Fracture Mechanics, Technical University of Denmark, 1979.

[28] F. Lagattu, F. Bridier, P. Villechaise, J. Brillaud, In-plane strain measurements on a microscopic scale by coupling digital image correlation and an in situ SEM technique, Mater. Charact. 56 (2006) 10-18.

[29] H. Wang, H. Xie, Y. Ju, Q. Duan, Error analysis of digital speckle correlation method under scanning electron microscope, Exp. Tech. 30 (2006) 42-45.

[30] M. Sjödahl, Accuracy in electronic speckle photography., Appl. Opt. 36 (1997) 2875-2885.

\section{List of symbols and abbreviations}

$a \quad$ notch root length (Fig. 5)

$d_{n} \quad$ parameter indicating the slope of $\delta_{t}$ versus $J$ (Eq.(6) and Eq.(7))

$f \quad$ facet size (subsection 3.6)

$h \quad$ width of the DCB test specimen beam (Fig. 5)

$n \quad$ hardening exponent (Eq. (1))

$l \quad$ field of view (subsection 3.6)

$p \quad$ facet step (subsection 3.6)

$r \quad$ radius drawn from the notch centre (Fig. 2)

$A \quad$ area of the cross section (section 1)

$B \quad$ thickness of specimen (Fig. 5)

DCB double cantilever beam (subsection 3.4)

DIC digital image correlation (subsection 3.6)

E elastic modulus

ESEM environmental scanning electron microscope (subsection 3.5)

$F_{u} \quad$ failure load at the macro-scale (section 1)

$J \quad J$ integral as a loading parameter (Eq. 1)

M moment (subsection 3.4)

$M_{T} \quad$ magnification factor (subsection 3.6)

$N \quad$ recording resolution (subsection 3.6)

$W \quad$ strain energy density (subsection 2.1, Eq. (4))

$\bar{W} \quad$ averaged $W$ around the notch (subsection 2.2, Eq. (8))

$\alpha \quad$ material constant (Eq. (1))

$\delta_{n}^{*} \quad$ normal opening of the crack faces (section 1)

$\delta_{t} \quad$ width of deformed notch (Fig. 2, Eq.(7))

$\delta_{t o} \quad$ initial notch width (determined for initially un-deformed notch in the same way as $\delta_{t}$ )

$\varepsilon \quad$ strain

$\varepsilon_{e} \quad$ von Mises strain (subsection 3.7, Eq. (14))

$\varepsilon^{p} \quad$ permanent strain (Fig. 3, Fig. 10)

$\varepsilon_{r r} \quad$ radial strain (subsection 3.7)

$\varepsilon_{r \theta} \quad$ angular shear strain (subsection 3.7)

$\varepsilon_{\theta \theta} \quad$ angular strain (subsection 3.7)

$\varepsilon_{o} \quad$ elastic strain (Fig. 3)

$\varepsilon_{u} \quad$ failure strain at the micro-scale (section 1)

$\tilde{\varepsilon}_{u} \quad$ failure strain at the macro-scale (section 1)

$\theta \quad$ angle

$\sigma \quad$ stress

$\hat{\sigma}_{n} \quad$ failure stress at the micro-scale (section 1)

$\sigma_{o} \quad$ yield stress (Fig. 3)

$\tilde{\sigma}_{u} \quad$ failure stress at the macro-scale (section 1) 


\section{Appendix: The accuracy of DIC measurements}

The specimen surface was observed to undergo brightness and contrast changes during the DCB test. First, the effect of lightning variations was evaluated increasing the brightness of a still image by $10 \%, 20 \%$, and 30 $\%$. The brightness variations did not create artificial strain; however, the noise of measurements slightly increased as a standard deviation of $0.05 \%$ was measured. Second, the contrast changes were related to the out-of-plane displacements, i.e. along the $z$-axis, which varied with the applied moment, and were estimated around 100-300 $\mu \mathrm{m}$. In order to evaluate the effect of out-of-plane displacements, not loaded specimens were displaced along the $z$-axis. The non-zero strains were measured for all strain components. The most sensitive was the effective strain, $\varepsilon_{e}$. For the strain components $\varepsilon_{\theta \theta}$ and $\varepsilon_{r r}$, artificial strains were not exceeding $0.42 \%$, and minor strains were measured for $\varepsilon_{\theta r}$. Results for different magnifications, $M_{G}$, are summarized in Table 5.

Table 5 Strains measured in the rigid body in-plane and out-of-plane displacement test

\begin{tabular}{cccccccc}
$\begin{array}{c}\text { Displacement } \\
{[\mu \mathrm{m}]}\end{array}$ & $\begin{array}{c}f \\
\text { [pixels }^{2} \text { ] }\end{array}$ & $\begin{array}{c}p \\
\text { [pixels] }\end{array}$ & $M_{G}$ & $\varepsilon_{e}[\%]$ & $\varepsilon_{\theta \theta}[\%]$ & $\varepsilon_{r r}[\%]$ & $\varepsilon_{r \theta}[\%]$ \\
\hline$\Delta \mathrm{x}=25$ & $60 \times 60$ & 5 & $\times 500$ & $0.17 \pm 0.08$ & $0.00 \pm 0.11$ & $0.00 \pm 0.10$ & $0.00 \pm 0.07$ \\
$\Delta \mathrm{x}=25$ & $45 \times 45$ & 3 & $\times 500$ & $0.31 \pm 0.15$ & $0.00 \pm 0.23$ & $0.00 \pm 0.20$ & $0.00 \pm 0.15$ \\
$\Delta \mathrm{x}=100$ & $60 \times 60$ & 5 & $\times 100$ & & $0.00 \pm 0.11$ & $0.00 \pm 0.11$ & $0.00 \pm 0.08$ \\
\hline$\Delta \mathrm{z}=100$ & $60 \times 60$ & 5 & $\times 500$ & $0.35 \pm 0.16$ & $-0.15 \pm 0.14$ & $-0.14 \pm 0.14$ & $-0.01 \pm 0.10$ \\
$\Delta \mathrm{z}=200$ & $60 \times 60$ & 5 & $\times 500$ & $0.61 \pm 0.26$ & $-0.26 \pm 0.22$ & $-0.27 \pm 0.21$ & $-0.02 \pm 0.15$ \\
$\Delta \mathrm{z}=300$ & $60 \times 60$ & 5 & x 500 & $1.02 \pm 0.50$ & $-0.37 \pm 0.44$ & $-0.42 \pm 0.44$ & $-0.01 \pm 0.31$
\end{tabular}

In addition, to evaluate possible errors due to distortions and in-plane displacements ( $x-y$ plane), the in-plane rigid body displacement tests were performed. According to the references [23,28,29], distortions can be caused by electromagnetic field fluctuations, time shift between scan lines, heating, charging of the SEM stage or specimen, and environmental factors (e.g. thermal fluctuations, mechanical vibrations, air currents, etc.). During the DCB test, displacements along the $y$-axis were measured up to $30 \mu \mathrm{m}$ and $150 \mu \mathrm{m}$ for the results acquired at magnification x 500 and x100, respectively. Similar displacements were used to perform the in-plane displacement tests. Results showed that the strain components are rather insensitive to in-plane displacements, and distortions were not found to affect the measurements, see also Table 5 . The only non-zero values were measured for $\varepsilon_{e}$, which seemed to be the most sensitive strain component to any displacements.

\section{The effect of measurement parameters}

According to Sutton et al. [17], in order to have an accurate matching during DIC analysis, speckles should be sampled by a 3 by 3 pixel array. For the images recorded in this study, the minimum particle diameter, $d_{p}$, was estimated of $1.8 \mu \mathrm{m}$ and $9 \mu \mathrm{m}$ for magnifications x500 and x100, respectively. The required $d_{p}$ partly overlaps with the actual particle size of 0.05-3 $\mu \mathrm{m}$, which was measured with laser diffraction method [18]. Apart from the laser diffraction measurements, the microscope images showed the presence of even larger particles, i.e., $d_{p}>3 \mu \mathrm{m}$.

Furthermore, according to Sutton et al. [17], the facet size, $f$, should contain at least 9-10 speckles, i.e. $f \geq 5.4$ $\mu \mathrm{m}$ and $f \geq 27 \mu \mathrm{m}$ for magnification $\mathrm{x} 500$ and $\mathrm{x} 100$, respectively. Practically, the minimum theoretical facet size, which gives the highest spatial resolution, was impossible due to high noise level and decorrelation. Even though, the spatial resolution was reduced with larger facets, the accuracy increased and the noise reduction 
was improved [30]. In this study, the images of the specimen surface were divided into facets with a length of 45-60 pixels $(f=[26 \mu \mathrm{m} ; 177 \mu \mathrm{m}]$, see Table 2$)$ and a distance between the centre points of the adjacent facets was set to 3-5 pixels ( $p=[3 \mu \mathrm{m} ; 15 \mu \mathrm{m}]$, see Table 2). The facet step was mainly responsible for how densely the facets are packed. More densely packed facet array will give more measurement points within the measurement area. At the same time, too much densely packed array can lead to higher measurement error as the area shared between adjacent facets is increased. In this study, the overlap between the adjacent facets was within the range of 92-93\%. Relatively far from the notch, neither the facet size nor the facet step, within the range given above, was affecting the measurements, i.e. only the variations of the measurement noise were observed. Slightly different situation was near the notch edge. Smaller facet step and facet size, first, made the strain variations around the notch more distinct (more profound strain peaks); second, close to the notch tip (at the distances smaller than $20 \mu \mathrm{m}$ from the notch tip), the strain values increased. In this study, the facet size and facet step was chosen as a compromise between sufficiently high spatial resolution, sufficient number of measurement points, fast computation time, and low noise level.

\section{The effect of magnification}

The strain measurements were observed to vary with the magnification, at which the images were recorded. The disagreement was particularly evident for the Test Series 1 as shown in Fig. 19. In Fig. 19 it can be seen that the strains acquired from the images captured at magnification x500 and x1000 agree with each other, but were in disagreement with the measurements gained from the images captured at magnification $\mathrm{x} 100$. Discrepancies were related to the differences in the spatial resolution (see Table 2). In this study, the images recorded at the magnification $\times 500$ were preferred, which were found as a compromise between sufficiently large field of view and high spatial resolution.

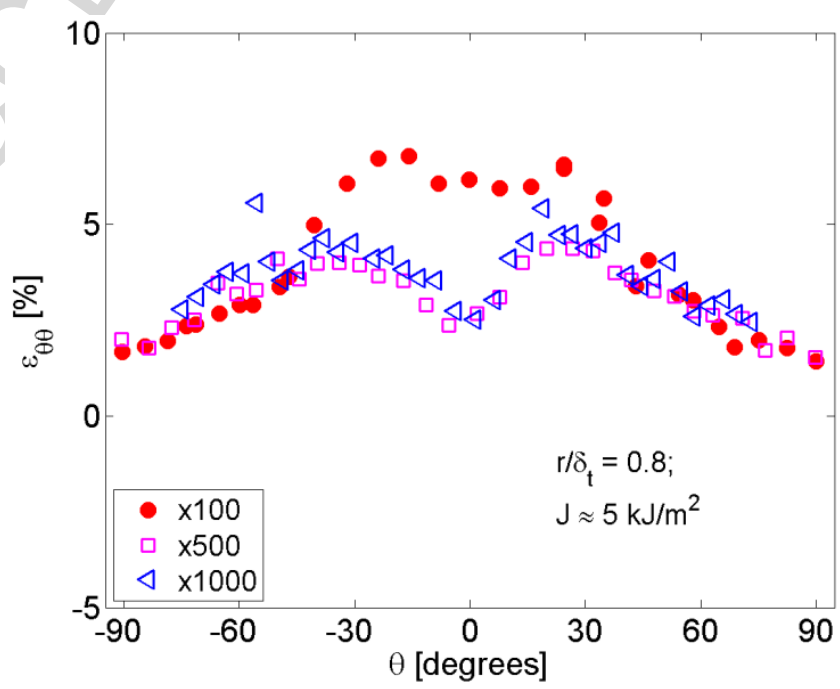

Fig. 19 Strains obtained from the images recorded at various magnifications for the Test Series 1 

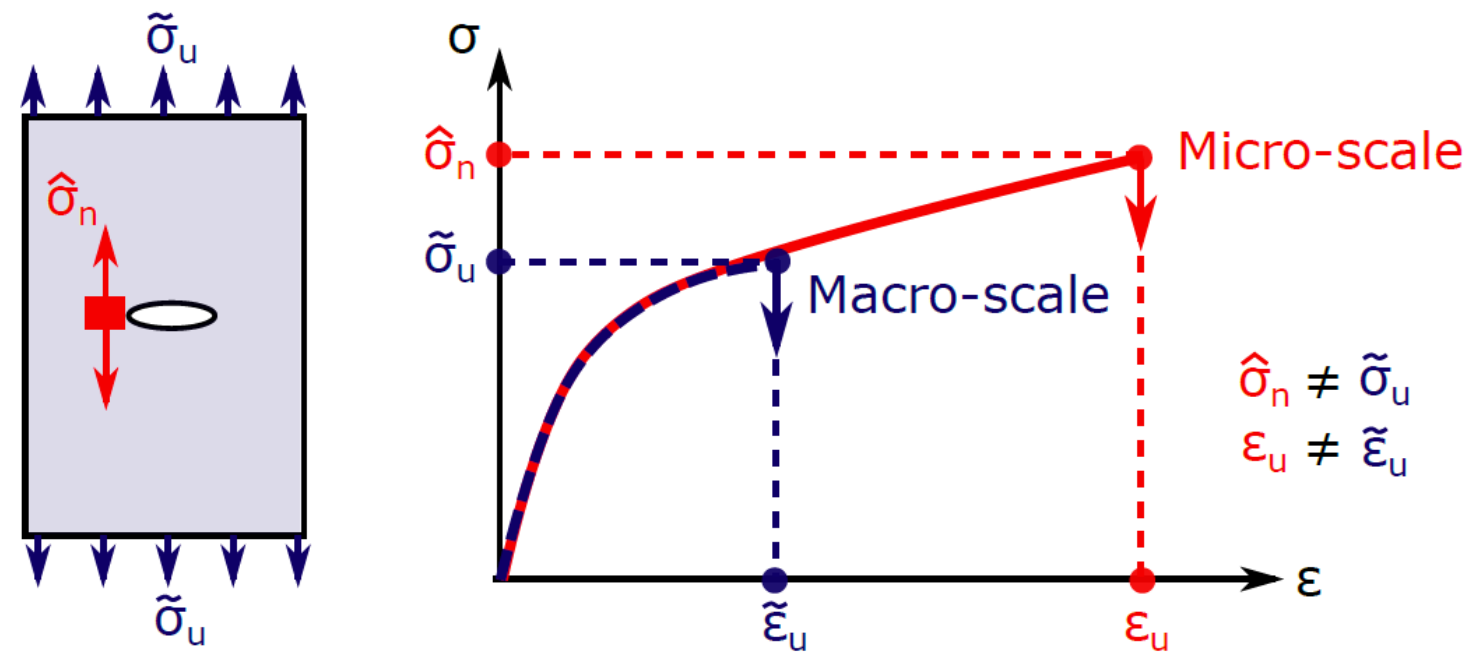

Graphical abstract

Highlights A macro-scale stress-strain relation is inappropriate for polymer/fibre composite micromechanical models.

1. Combining the micro-scale experiments and concepts of nonlinear fracture mechanics, a method to determine the micro-scale stress-strain law is presented.

2. Before failure, the micro-scale strains in the epoxy reached reached $20 \%$ and the stress was estimated around 220-300 MPa.

3. The micro-scale failure strain and stress of the epoxy were 3-4 times greater than the macroscale values.

4. An approach to compare strain fields around various notches normalizing all length parameters with the width of deformed notch was experimentally validated. 